\title{
Coordination under threshold uncertainty in a public goods game
}

Astrid Dannenberg, Andreas Löschel, Gabriele Paolacci, Christiane Reif and Alessandro Tavoni

November 2011

Centre for Climate Change Economics and Policy Working Paper No. 74

Grantham Research Institute on Climate Change and the Environment Working Paper No. 64 
The Centre for Climate Change Economics and Policy (CCCEP) was established by the University of Leeds and the London School of Economics and Political Science in 2008 to advance public and private action on climate change through innovative, rigorous research. The Centre is funded by the UK Economic and Social Research Council and has five interlinked research programmes:

1. Developing climate science and economics

2. Climate change governance for a new global deal

3. Adaptation to climate change and human development

4. Governments, markets and climate change mitigation

5. The Munich Re Programme - Evaluating the economics of climate risks and opportunities in the insurance sector

More information about the Centre for Climate Change Economics and Policy can be found at: http://www.cccep.ac.uk.

The Grantham Research Institute on Climate Change and the Environment was established by the London School of Economics and Political Science in 2008 to bring together international expertise on economics, finance, geography, the environment, international development and political economy to create a world-leading centre for policyrelevant research and training in climate change and the environment. The Institute is funded by the Grantham Foundation for the Protection of the Environment, and has five research programmes:

1. Use of climate science in decision-making

2. Mitigation of climate change (including the roles of carbon markets and low-carbon technologies)

3. Impacts of, and adaptation to, climate change, and its effects on development

4. Governance of climate change

5. Management of forests and ecosystems

More information about the Grantham Research Institute on Climate Change and the Environment can be found at: http://www.Ise.ac.uk/grantham.

This working paper is intended to stimulate discussion within the research community and among users of research, and its content may have been submitted for publication in academic journals. It has been reviewed by at least one internal referee before publication. The views expressed in this paper represent those of the author(s) and do not necessarily represent those of the host institutions or funders. 


\title{
Coordination under threshold uncertainty in a public goods game
}

Astrid Dannenberg ${ }^{\mathrm{a}}$, Andreas Löschel ${ }^{\mathrm{a}}$, Gabriele Paolacci ${ }^{\mathrm{b}}$, Christiane Reif ${ }^{\mathrm{a}}$, and Alessandro Tavoni $^{\mathrm{c}}$

${ }^{\text {a }}$ Centre for European Economic Research (ZEW), Mannheim, Germany. Dannenberg: dannenberg@zew.de; Löschel: Loeschel@zew.de; Reif: reif@zew.de

${ }^{\mathrm{b}}$ Ca' Foscari University of Venice, Italy. paolacci@ unive.it

${ }^{\mathrm{c}}$ Grantham Research Institute on Climate Change and the Environment, LSE, London, UK. ; A.Tavoni@1se.ac.uk

\begin{abstract}
We explored experimentally how threshold uncertainty affects coordination success in a threshold public goods game. Whereas all groups succeeded in providing the public good when the exact value of the threshold was known, uncertainty was generally detrimental for the public good provision. The negative effect of threshold uncertainty was particularly severe when it took the form of ambiguity, i.e. when players were not only unaware of the value of the threshold but also of its probability distribution. Early signaling of willingness to contribute and share the burden equitably helped groups in coping with threshold uncertainty.
\end{abstract}

Keywords: public good, threshold uncertainty, ambiguity, experiment

JEL classification: C72, C92, H41, Q54

Acknowledgements: We are grateful to Scott Barrett, Raphael Calel, Simon Dietz, Francois Laisney, and Oliver Walker who commented on a previous draft. We are also indebted to the participants of seminars held in Belpasso, Columbia, Magdeburg, Mannheim and Oxford for their comments. We thank the MaXLab team at Magdeburg for their support in conducting the experiment. This work was financially supported by the German Science Foundation and the Gottfried Wilhelm Leibniz Scientific Community. 


\section{Introduction}

Many natural resources involve threshold effects. Using these resources beyond a tipping point can have disastrous consequences for the environment and human well-being (Lenton et al. 2008). Prominent examples are related to catastrophic climate change, such as the collapse of the Atlantic Thermohaline Circulation or the decay of the Greenland ice sheet, and the collapse of natural resources, such as fish stocks, grassland, or forests. The potentially dangerous consequences have led to a political consensus about the urge of avoiding such thresholds. However, these natural tipping points entrench high uncertainty (Kriegler et al. 2009, Alley et al. 2003, Scheffer et al. 2001) which may seriously affect people's willingness to cooperate in order to prevent catastrophes.

In this work, we explored the effect of uncertainty on agents' ability to coordinate their cooperative efforts in order to prevent a collective damage. To this end, we conducted a laboratory experiment involving a threshold public goods game. In a typical threshold public goods game, each player in a group receives an endowment and decides how much of it to contribute to a public good. If the group contribution exceeds a certain threshold, then the public good is provided and each player receives a fixed amount of money, no matter how much she contributed to the public good. If the threshold is not reached, contributions are not returned to the players. ${ }^{1}$

Threshold public goods games have been studied theoretically for a long time, and in particular it is known that differently from continuous public goods games, Pareto-optimal outcomes are supportable as Nash equilibria (Bagnoli and Lipman 1989, Palfrey and Rosenthal 1984). Uncertain thresholds, however, can lead to free-riding and ultimately to

\footnotetext{
${ }^{1}$ There are also threshold public goods games with refunding if the provision point is not met (e.g. Spencer et al. 2009, Rondeau et al. 2005) or a rebate beyond the provision point (e.g. Isaac et al. 1985). For an overview see Croson and Marks (2000).
} 
inefficient equilibria (Nitzan and Romano 1990, Suleiman 1997). McBride (2006) considered changes in the probability distribution of the threshold under various public good values. $\mathrm{He}$ found that voluntary contributions do not relate monotonically to uncertainty. In particular, increasing uncertainty through a mean-preserving spread leads to higher contributions if the value of the public good is sufficiently high. On the other hand, an increase in uncertainty leads to lower contributions if the public good value is relatively low. Barrett (2011b) showed that threshold uncertainty changes the nature of the cooperation problem in a climate change game. Provided that the climate change damage is large (compared to the costs of avoiding it) and the threshold is certain, the challenge requires only coordination of efforts because preventing the damage is both collectively optimal and a Nash equilibrium. With threshold uncertainty, in contrast, cooperation is needed and difficult to enforce because the social optimum is not supportable as Nash equilibrium.

Some experimental studies tried to shed further light on how uncertainty affects cooperative outcomes. McBride (2010) found that threshold uncertainty hampers cooperation when the value of the public good is relatively low, although the opposite can happen for higher public good values. It has also been shown that the effect of threshold uncertainty can depend on the mean of the threshold distribution, such that uncertainty helps (hinders) cooperation when the mean is high (low) (Suleiman et al. 2001). Whereas Kotani et al. (2010) confirmed that high levels of threshold uncertainty hamper cooperation, their evidence suggests that moderate levels of uncertainty can be beneficial. Environmental uncertainty has also been explored by researchers in resource dilemmas, who generally found that uncertainty is detrimental for collective outcomes. The more uncertain people are regarding the size of the available resource, the more likely they are to overharvest from that resource (Budescu et al. 1990, Gustafsson et al. 1998, Rapoport et al. 1992, Wit and Wilke 1998). 
These previous experiments manipulated uncertainty solely by widening the threshold interval (or the resource or group size), thus ignoring the potential peculiarities of different kinds of threshold distribution. Moreover, to the best of our knowledge, there has been no investigation of the effect of threshold ambiguity: How are collective outcomes in a threshold public goods game affected if the probability distribution of the threshold is unknown to the players?

The debate on the distinction between risk (known probability distribution) and ambiguity (unknown probability distribution) has a long theoretical tradition (Knight 1921, Savage 1954). Starting from the Ellsberg paradox (Ellsberg 1961) researchers have begun to explore extensively individuals' attitudes and behavioral responses toward ambiguity, typically revealing aversion to situations in which probabilities are unknown (e.g., Chow and Sarin 2002, Slovic and Tversky 1974; see Camerer and Weber 1992 for a review). Some authors explored how behavior in games changes when players' perception of others' decisions is ambiguous (Bailey, Eichberger, and Kelsey 2005, Eichberger and Kelsey 2002, Eichberger, Kelsey, and Schipper 2008), and found that players cope with strategic ambiguity by choosing more secure actions. However, we found no evidence on the consequences of environmental ambiguity, e.g. how ignoring the probability distribution of the threshold affects players' behavior in a public goods game.

In our laboratory experiment we compared how coordination success in a threshold public goods game was affected by whether the threshold was known or not. In particular, we employed four different forms of threshold uncertainty. Whereas two experimental treatments involved risk, as the threshold was a random variable with known probability distribution, two other treatments involved ambiguity, as the probability distribution of the threshold was unknown. 
A prominent goal of our study was to reproduce those real-world setups in which agents such as individuals or communities need to coordinate their cooperative efforts in order to prevent an undesirable event. Accordingly, our setup deviated from traditional threshold public goods games in three important ways. First, players contributed to the common account not to realize a gain but to avoid a loss. If the group contribution did not reach a certain amount of money, all members lost almost all of their remaining endowments. Second, the provision of the public good was sequential, as the assessment of the group effectiveness in preventing the public bad was carried out only after multiple stages of contributions. This allowed for the examination of how players in a group reacted to the fellow members' behavior under different uncertainty configurations. Third, we implemented a simple possibility to communicate, as players could suggest non-binding proposals for the group's targeted contribution (Tavoni et al. 2011).

Lastly, note that a threshold public goods game like this one differs from the majority of games used to investigate global environmental cooperation problems (Finus 2001). Specifically, the problem of enforcement is facilitated by the "disastrous" consequences of contributing less than the threshold. The traditional formulation, in contrast, does not include catastrophes but only gradual effects.

Our experimental data indicate that threshold uncertainty was detrimental for the provision of the public good. Whereas all groups succeeded in preventing the public bad when the threshold was known, this result was not replicated in the presence of threshold uncertainty. Although the contribution pattern differed depending on how uncertainty was configured, contributions were generally lower when players did not know ex-ante the exact threshold value. Critically, contributions were particularly low and erratic in the treatments involving ambiguity. We also found that early signaling of willingness to contribute and share the 
burden equitably made groups more likely to reach a high public good provision level, even in the presence of threshold uncertainty.

The paper is organized as follows: Section 2 describes in detail our game and the experimental design and procedures. Section 3 discusses the equilibria of the game. Section 4 presents our results and Section 5 concludes.

\section{The Game}

Our game shares certain features with the decision setup developed by Milinski et al. (2008) and extended by Tavoni et al. (2011). At the beginning of the experiment, subjects were endowed with $€ 40$ and randomly assigned to groups of 6 anonymous players. The groups remained unchanged throughout the session. The experiment was composed of 10 rounds. In each round, players decided how much of their private endowment to contribute to a common account between $€ 0, € 2$, and $€ 4$. Players knew that if the group contribution at the end of the 10 rounds failed to reach or exceed some threshold, each player would lose $90 \%$ of her remaining endowment. This means that failing to reach the threshold would leave players with only $10 \%$ of their private savings as opposed to $100 \%$. After each round players were informed about the contributions of all individuals and of the group, both in the current round and cumulated. At round 1 and round 6, players could make non-binding proposals to the group regarding the collective contribution to reach, which were also notified to the group.

Subjects in our experiment were randomly assigned to one of five different treatments. In a control treatment ("Baseline") the contribution threshold was certain. Players knew that if the group failed to contribute $€ 120$ or more after 10 rounds, all members would be paid only $10 \%$ of their remaining private endowments. In the treatments with uncertainty, in contrast, players did not know in advance the threshold that had to be reached in order to prevent the public 
bad, i.e. to keep their private savings. Specifically, the players were confronted ex-ante with several potential thresholds; each of them could become the ex-post threshold with a certain probability. Unlike previous experiments on threshold uncertainty, we kept the threshold interval constant across treatments. In particular, the discrete threshold probability functions were described over 13 potential thresholds ranging from $€ 0$ to $€ 240$ in $€ 20$ increments. Note that the $[€ 0, € 240]$ interval implied both that the public bad might be avoided with zero contributions and that the public bad might occur even if all six players contribute their entire $€ 40$ endowment (thus becoming indifferent to the occurrence of the public bad). At the end of the experiment, the threshold was determined through a ball picking task: A participant volunteered to publicly pick one small plastic ball out of many, which determined the threshold value. Subjects were paid either $100 \%$ or $10 \%$ of their remaining endowments, depending on whether their group had reached the threshold contribution or not.

We implemented four treatments with threshold uncertainty. Figure 1 illustrates the frequency distribution of the balls. There were two treatments involving risk, which had the same expected value of the threshold (€120) but different probability distributions. One treatment ("Triangular") involved a symmetric triangle-shaped probability density function clustered around the single mode of $€ 120$. The other treatment involving risk ("Uniform") was based on a flat uniform distribution, meaning that all potential threshold values were equally likely.

We also implemented two treatments in which subjects faced ambiguity. That is, not only players could not know the threshold with certainty, they were also ignorant about the probability distribution of the threshold. Such treatments were seemingly related to the risk treatments in that we added additional "noise". However, we also wanted to vary how confident people would likely feel about the ultimate probability distribution of the threshold, arguably capturing different "levels of ambiguity". In one such treatment (“AmbTriangular"), 
the 12 subjects who entered the lab were asked to choose one out of 13 colors on a paper sheet. Knowing that all individuals had made this decision (but not knowing the others' decisions), subjects were subsequently informed that each choice identified the color of an additional ball to be added to a triangle-shaped frequency of balls similar to the one in the Triangular treatment (see Figure 1). In the second ambiguity treatment (“AmbUniform”), one randomly selected subject was asked to go into another room in order to complete a brief task and wait until the end of the session. The task was to distribute 50 balls over a blank matrix on a paper sheet (without knowing the purpose). The student was explicitly informed that he or she had complete freedom of choice and that the balls could be distributed in any way, e.g. symmetric or asymmetric. The resulting distribution determined the probability distribution of the threshold. The remaining participants were informed about this procedure and thus played the game without knowing the threshold probability distribution.

Table I summarizes the experimental design. Note that there was no information asymmetry between experimenters and subjects, meaning that the former were also ignorant about the probability distribution determined via the tasks. This is an important feature of our design for two different reasons. First, decision makers perceive ambiguity differently when there is somebody else (e.g. the experimenter) who has more information or not (Chow and Sarin 2002). Second, the environmental uncertainty that revolves around tipping points is typically one of the "unknowable" type, as nobody has nor could have more information than decision makers. Validity concerns thus imposed to implement a procedure in which subjects and experimenters had the same information regarding the threshold distribution.

The experiment was conducted in a computer lab at the University of Magdeburg, Germany. In total, 300 subjects participated in the experiment, recruited from the general student population (recruitment software ORSEE, Greiner 2004). Subjects earned $€ 13.08$ on average 
including a show-up fee of $€ 2.00$. Sixty subjects participated in each treatment. Subjects in each experimental session were assigned to the same treatment. Each subject was seated at linked computer terminals that were used to transmit all decisions and payoff information (game software Z-tree, Fischbacher 2007). Once subjects were seated, a set of written instructions was handed out. Experimental instructions (see Appendix) included numerical examples and control questions in order to ensure that subjects understood the game. An oral presentation highlighted the key features of the game and provided further numerical examples before the game started. After the final round, subjects completed a short questionnaire that elicited, among other things, their motivation during the game (see Table SIII in the Appendix).

\section{The Equilibria}

The game can be analyzed in the framework of expected payoff maximization, as follows. All players $N=\{1, \ldots, n\}$ have symmetrical strategy sets $C_{i}$ and make simultaneous contribution choices in each round belonging to $R=\{1, \ldots, r\}$. The contribution threshold $T$ needed to provide the public good (after the final round has been played and $r$ successive contributions $c_{i}^{t}$ have been made in each round $t \in R$ by the $n$ players, yielding $\left.I=\sum_{t=1}^{r} \sum_{j=1}^{n} c_{j}^{t}\right)$, comes from a cumulative distribution function $F_{I}(T)$. Given a profile $c$ of contributions in the entire game, player $i$ 's expected payoff is $\pi_{i}(c)=F_{I}(T)\left(w-\sum_{t=1}^{r} c_{i}^{t}\right)+\left(1-F_{I}(T)\right)\left(w-\sum_{t=1}^{r} c_{i}^{t}\right) d$, where $w$ is players' endowment and $d$ is the percentage of private moneys that a player keeps if the threshold is not reached.

In the game, we tested $n=6, C_{i}=\{0,2,4\}$ in each round $(r=10), w=40$ and $d=10 \%$. Whereas in Baseline $T=120$ with certainty, in Triangular and Uniform $T$ is a discrete 
random variable with $E(T)=120$ and increasing dispersion around the first moment. ${ }^{2}$ Recalling that, with the exception of Baseline, the requirement to provide the public good is no longer to reach a fixed sum of $€ 120$ but rather to tackle a probabilistic threshold given different sets of information, one can reason in terms of the investment $I^{*}$ that maximizes the group's expected payoff. Figure 2 gives a graphical representation of the provision probability for each threshold in Baseline, Triangular and Uniform.

A salient feature of our game is that the value of the public good decreases with contributions. When players have already contributed a substantial share of their endowments, the public good is of low value because the players have little left in their private accounts, and thus little to lose. Therefore, the right tail of the distribution does not matter as much as the left tail, where players have much to lose. This is why Uniform is characterized by lower optimal contributions $I^{*}=100$ than the other treatments as highlighted in Figure 3 and Table II.

Consider first the two risk treatments with uncertain threshold but known probability (center and right panels in Figure 3). When the group collectively increases contributions $I$ to target a higher threshold, the benefits from the investment increase, as the likelihood that the ex-post drawn threshold is reached ( $T \leq I)$ increases. However, also the ensuing costs increase, more steeply on the right side of the figures. The leftmost panel in Figure 3 concerns the Baseline treatment. In it, because of the certainty of the threshold $(T=120)$, group benefits sharply jump from $€ 24$ when the threshold is not reached (given the $90 \%$ loss) to $€ 240$ when it is reached. Again, investments are initially relatively less costly (angular coefficient $=0.1$ ), and become steeper from $I=120$ onwards (angular coefficient $=1$ ).

\footnotetext{
${ }^{2}$ Note that, while in Baseline $F_{I}(T)=0$, if $I<120$ and $F_{I}(T)=1$, if $I \geq 120$, in the risk treatments $F_{I}(T)>0$ for each investment level (i.e. there is a positive provision probability even for $I=0$ ). On the other end of the spectrum, only $I=240$ guarantees provision in the Triangular and Uniform, which would leave each player with $w-\sum_{t=1}^{r} c_{i}^{t}=0$. The coordination problem is therefore more complex in the risk treatments.
} 
Comparing the expected costs and benefits in Figure 3, it becomes apparent that the coordination challenge becomes harder with increasing dispersion around the mean, i.e. from Baseline to Triangular to Uniform. First of all, while in Baseline there are only two pure strategy Nash equilibria around which groups can coordinate ( $I=0$ and $I=120$, with the latter payoff-dominating the former), there are many under threshold uncertainty. The $I=120$ contribution level is somewhat less focal in the risk treatments, since it is no longer the case that any contributions below or above $€ 120$ are wasted. In particular, each of the seven thresholds between 0 and 120 inclusive are Nash equilibria. ${ }^{3}$ The zero contribution strategy $I=0$ is again a payoff-dominated Nash equilibrium, since unilateral deviations lower a player's expected payoff. Moreover, the expected payoff does not change as abruptly when moving from one value of $I$ to another one in Triangular and Uniform (i.e. the net benefits of choosing $I=120$ over $I=0$ or any other value of $I$ are less marked than in Baseline). Lastly, the maximum group payoff (which is given by the vertical distance between the benefits and costs curves) drops from $€ 120$ in Baseline to $€ 74$ in Triangular, both achieved at $I^{*}=120$ (implying a probability of provision of 1 and 0.57 , respectively). In Uniform, the maximum expected payoff is $€ 72$, when $I^{*}=100$ and the probability of provision is 0.46 .

Table II reports the expected payoffs from following a pure symmetric strategy as well as from following the optimal symmetric contribution, i.e. the one leading the group to reach $I^{*}$. In sum, we have established that groups are best off with positive contributions of either $€ 2 /$ round, or slightly less in Uniform. (But note that the expected payoff from contributing $€ 2 /$ round, $€ 11.7$, is close to the maximal attainable value $€ 12.0$ ). These provision levels that maximize the (expected) joint payoff are supportable as Nash equilibria in all treatments. However, there also exist other payoff-dominated equilibria; hence an equilibrium selection

\footnotetext{
${ }^{3}$ Moreover, in Triangular, provided that in the first nine rounds investments have amassed to $€ 128, C=2$ is the dominant strategy in round 10 . So 140 may be also a Nash equilibrium under these conditions. This is not the case in Uniform, as exemplified in Table SI and Table SII in the Appendix.
} 
problem exists. ${ }^{4}$ Therefore, rather than testing precise theoretical hypotheses, the purpose of our experiment is more explorative and empirical: Can subjects reach the 'best' equilibrium when there are many (i.e. reach a target when it is uncertain)? We resort to the empirics to answer this question. In a similar fashion, we discover if groups are able to reach a high public good provision level when they face ambiguity. Expected utility theory cannot be of much guidance in the ambiguity treatments since the experimenter is unaware of the subjects' prior. However, the $€ 120$ threshold arguably is a natural focal point in all treatments. It is not only the certain threshold in the Baseline treatment and the expected value of the threshold in the two risk treatments, but it is also the midpoint of the $[0,240]$ interval and the collective outcome if all the players choose the intermediate $€ 2 /$ round strategy.

\section{Results}

Table III presents the summary statistics of the experimental data averaged across groups per treatment. The contributions to the public good decreased from the certainty (Baseline) to risk (Triangular, Uniform) and from risk to ambiguity (AmbTriangular, AmbUniform). A series of Wilcoxon rank-sum tests confirms that subjects in Baseline contributed significantly more than those in the other treatments $\left(\mathrm{p}<0.01\right.$ for each treatment, see Table IV). ${ }^{5}$ Thus, threshold uncertainty hampered cooperative efforts in our game.

The average proposals for the group target, shown in the first and second column of Table III, were close to $€ 120$ and do not significantly differ between treatments (Wilcoxon rank-sum test $\mathrm{p}>0.1$ for each treatment and both proposals). In all treatments except for Baseline, that is

\footnotetext{
${ }^{4}$ Note that this characteristic is due to the discrete nature of our probability distribution of the threshold (see Barrett 2011b for the effects of a continuous distribution).

${ }^{5}$ Statistical tests are based on group averages as units of observation. If not stated otherwise, the reported tests are two-sided throughout the paper. Note also, that the differences between Baseline and the other treatments are always significant at any conventional significance level and robust to multiple comparison corrections.
} 
whenever uncertainty was involved, contributions were markedly lower than proposals. That is, when facing uncertainty, subjects contributed significantly less than what they had proposed before (Wilcoxon Signed-Rank test $\mathrm{p}<0.01$ for each treatment and both proposals). This may suggest that although players had a similar approach to the game, uncertainty ultimately affected their behavioral responses.

The experiment was designed in order to examine the effects of uncertainty on subjects' ability to avoid a collective damage. However, the groups' actual effectiveness in avoiding the damage depended on the random draw in the experimental sessions. A group that was successful in its own session might have been unsuccessful in another session, and vice versa. In order to elaborate on groups' comparative performance, Table V shows the percentages of groups that would have succeeded in avoiding the damage at different hypothetical thresholds given their contributed amounts in the experiment. The results indicate that all groups would have succeeded at a threshold of $€ 20$ and none would have succeeded at $€ 160$. Between these two values there are remarkable treatment differences. Consider the focal $€ 120$ threshold. In Baseline, all groups reached the threshold successfully, with $7 / 10$ groups contributing exactly $€ 120$. In the risk treatments, Triangular and Uniform, 2/10 groups would have succeeded at a threshold of $€ 120$. In AmbTriangular 1/10 group would have succeeded while no group would have reached this threshold in AmbUniform. Compared to the $100 \%$ success rate in Baseline, these differences in percentages of successful groups are highly significant (one-sided Fisher's exact probability test $\mathrm{p}<0.01$ for each treatment). Furthermore, the groups in the risk treatments were (at least in expected terms) more successful than those in the ambiguity treatments.

The coordination of contributions towards a certain threshold obviously was not too difficult. In fact, all groups under certainty reached the threshold and many of them exactly met it. 
Notably, the variance of the group contributions increased significantly from certainty to risk and ambiguity, as the group performance varied widely under uncertainty (see Tables III and 4). What did determine the group performance in these treatments? Let us first consider the players' proposals for the group target. Table III shows that under uncertainty the average contributions always fell short of the average proposals. Only $1 / 40$ group (in the AmbTriangular treatment) managed to collect the amount proposed by the group members prior to the game. Still, proposals might have helped the subjects to coordinate their efforts insofar as higher proposals might have led to higher contributions even if the latter did not reach the former. Figure 4 shows the correlation between the average proposal and the group's total investment. It indicates that the correlation depends on the treatment. While the gap between proposals and actual investment was generally small in the two risk treatments, it was larger in the two ambiguity treatments, especially when looking at the first proposal. A series of Pearson correlation tests confirms an at least weakly significant positive correlation between the average first proposal by a group and its investment for Triangular $(\rho=0.88$, $\mathrm{p}=0.001)$ and Uniform $(\rho=0.58, \mathrm{p}=0.076)$ but reveals no significant correlation for AmbTriangular $(\rho=-0.07, \mathrm{p}=0.843)$ and AmbUniform $(\rho=0.24, \mathrm{p}=0.510){ }^{6}$ The same is true for individual proposals. The individual first proposals and individual contributions to the public good are significantly correlated in Triangular $(\rho=0.55, \mathrm{p}=0.000)$ and weakly significantly correlated in Uniform $(\rho=0.25, \mathrm{p}=0.057)$, while there is no significant correlation in AmbTriangular $(\rho=0.02, \mathrm{p}=0.906)$ and AmbUniform $(\rho=0.13, \mathrm{p}=0.322)$. A direct comparison between treatments by a test of equal correlations indicates significant differences between Triangular and AmbTriangular (group level: $\mathrm{p}=0.011$, individual level: $\mathrm{p}=0.001$ ) and between Triangular and AmbUniform (group level: $\mathrm{p}=0.036$, individual level: $\mathrm{p}=0.009$ ). Figure 4

\footnotetext{
${ }^{6}$ All the results on the correlation between variables do also hold if we employ the Spearman's rank correlation test.
} 
shows furthermore that the gap between the average proposal and actual contributions became smaller for the second proposal, indicating that the subjects adjusted their proposals downwards to what proved to be feasible after the first half of the game.

If subjects ex-ante made similar contribution plans across treatments, why did they actually invest less when faced with uncertainty? To answer this question we consider the first round of the game. This round shows players' decision without any feedback about their co-players' actions, and therefore is informative regarding players' unconditional willingness to contribute. Figure 5 shows the correlation between early action, defined here as the average group contribution undertaken in the first round, and the contributions provided in all the subsequent rounds. The correlation depends, again, on the treatment. While there is no significant correlation in Triangular $(\rho=0.21, \mathrm{p}=0.552)$, early action and subsequent contributions are positively and significantly correlated in Uniform $(\rho=0.72, \mathrm{p}=0.019)$, AmbTriangular $(\rho=0.69, \mathrm{p}=0.026)$, and AmbUniform $(\rho=0.78, \mathrm{p}=0.008) .^{7}$ Thus, when players were confronted with a high degree of uncertainty, they reacted very sensitively to their coplayers' behavior at the beginning of the game.

This observation leads to the next salient question: How likely was a low first round investment in the different treatments? The average group contribution in the first round is $€ 11.8$ in Baseline, €11.6 in Triangular, €11.6 in Uniform, €9.8 in AmbTriangular, and €10.6 in AmbUniform. Thus, the groups faced with ambiguity started the game with slightly lower contributions than the groups under certainty or risk. The combination of little early action and players' sensitivity to the first round behavior explains the poor performance of some groups in these treatments. To illustrate this, consider the group that provided the smallest amount (€26) of all groups taking part in the AmbUniform treatment (and of all groups taking

\footnotetext{
${ }^{7}$ In the Baseline treatment, the correlation between early action and subsequent contributions is also highly significant but negative $(\rho=-0.84, \mathrm{p}=0.002)$, reflecting the presence of groups that had a slow start but ultimately strived and managed to reach the threshold.
} 
part in the experiment). This group started in the first round with only $€ 6$ allocated to the public good. In contrast, the group with largest investment after ten rounds in AmbUniform (€118) provided $€ 14$ in the first round. Put differently, the difference in contributions between these two groups increased in the course of the game from $€ 8$ in the first round to $€ 92$ in the last round. In the AmbTriangular treatment, the group with the lowest overall investment (€36) provided only $€ 6$ in the first round, while the one with highest overall investment (€120) contributed $€ 12$ in the first round. Thus, the difference between these two groups increased from $€ 6$ at the beginning to $€ 84$ at the end of the game. On the other hand, the Uniform treatment, characterized by a similar relevance of the first round but higher overall investment, owed much of it to many groups starting the game with relatively high contributions (see Figure S1 in the Appendix).

The minimum first round contribution across all groups taking part in the experiment was $€ 6$, the maximum was $€ 14$. Although the difference is substantial for a single round, the groups with a low first round contribution could have easily made up for that during the nine remaining rounds. Still, this did not happen. Most groups taking early action, as defined in Figure S1 by investing at least $€ 12$ in the first round, did so because all of their members invested at least $€ 2$. About one-third of these groups (11/31) contained exactly one free-rider who gave nothing and was compensated by the co-players' contributions. None of these groups contained more than one free-rider. Thus, most of these groups started the game with a high contribution level and with an equally shared burden. The latter, in particular, might have helped to keep the group's motivation up for the remaining rounds. To test this hypothesis we calculate the normalized Gini coefficient for the first round as well as the average normalized Gini coefficient across all rounds. ${ }^{8}$ Both coefficients are positively correlated $(\rho=0.64$,

\footnotetext{
${ }^{8}$ The average Gini coefficient was calculated as follows:
} 
$\mathrm{p}=0.000$ ), indicating that an equal burden sharing in the first round was likely to be followed by an overall equal burden sharing. The average normalized Gini coefficient across all rounds is 0.09 for Baseline, 0.16 for Triangular, 0.18 for Uniform, and 0.22 for both ambiguity treatments. That is, inequality within groups tended to be higher under uncertainty. Figure 6 presents the correlation between inequality, i.e. the average normalized Gini coefficient across all rounds, and total investment. As could be expected from the above discussion, the correlation depends on the treatment. It is negative and highly significant in Uniform ( $\rho=-$ 0.94, $\mathrm{p}=0.000)$, AmbTriangular $(\rho=-0.93, \mathrm{p}=0.000)$, and AmbUniform $(\rho=-0.87, \mathrm{p}=0.001)$ while it is not significant in Baseline $(\rho=0.03, \mathrm{p}=0.945)$ and Triangular $(\rho=-0.44, \mathrm{p}=0.206)$. The direct comparison between treatments reveals that the differences in correlations between Baseline and Triangular, on the one hand, and Uniform, AmbTriangular, and AmbUniform, on the other, are at least weakly significant $(\mathrm{p}<0.1$ each).

Table VI presents a series of linear regressions of the cumulative group investment. ${ }^{9}$ Columns 1 and 2 capture the investment over the entire game, while Columns 3 and 4 capture the rounds 2-10 only, because these models include the first round investment as regressor. Columns 2 and 4 exclude the Baseline treatment in order to highlight the effects of the independent variables under uncertainty. All independent variables as well as the dependent variable are defined at group level. The results qualify the relationship we have identified between uncertainty and group investment. The groups in Baseline contributed more to the

$$
G^{+}=\left(\frac{2 k \sum_{j=1}^{n} \sum_{t=1}^{r} c_{j}^{t}}{n \sum_{t=1}^{r} \sum_{t=1}^{r} c_{j}^{t}}-\frac{(n+1)}{n}\right) \frac{n}{(n-1)}
$$

where $k$ is the rank of individual contributions within a group, when contributions are considered in an ascending order.

${ }^{9}$ The regression models include the questions about the players' motivation for their proposal for the group target, the motivation for their investment decisions, and the question about fairness consideration (see Table SIII in the Appendix). All other variables taken from the questionnaire, for example risk aversion, trust, and analytical skills, have been excluded because the pre-regression analysis has shown that these characteristics did not significantly affect players' behavior. 
public good than those in all the other treatments, and the difference is highly significant between Baseline and Uniform and between Baseline and the two ambiguity treatments. The groups in Triangular contributed more than those in the ambiguity treatments.

In addition, contributions were significantly larger when the groups had made a larger second proposal. This effect is not observed for the average first proposal, which confirms that this proposal did not serve as a good signal for the group performance. The two regression models including the first round investment as regressor confirm that a high first round investment was only important for the groups facing uncertainty. Another interesting question is whether fairness considerations affected the group performance. $37 \%$ of the players reported in the questionnaire that fairness did not play a role in their investment decision. For the other players, the impact of fairness was either positive or negative; players either increased their contributions when they had observed a high investment level within their group (6\%) or, more likely, they decreased their contributions when they had observed a low investment level (31\%) (see Table SIII in the Appendix). In line with these statements, the regression analysis shows that the group performance suffered from a high number of members reporting negative impacts of fairness. These findings indicate that an unequal burden sharing really lowered players' willingness to cooperate.

Table SIV in the Appendix presents the results from a series of linear regressions of the cumulative individual contributions to the public good. The regression results basically confirm all key findings.

\section{Conclusions}

Science tells us that the climate system and other natural resources involve tipping points, beyond which potentially catastrophic and irreversible consequences to our planet may ensue. 
However, these tipping points and the efforts required to avoid triggering them are highly uncertain. Although there is widespread political consensus about the need to avoid passing such thresholds, countries' willingness to contribute to this collective goal may be seriously affected by environmental uncertainty. We designed an experiment involving a threshold public goods game to compare how collective action is affected by whether the threshold is known or not. The challenge of the game is always one of coordinating public good contributions because the provision level that maximizes the expected joint payoff is supportable as Nash equilibrium. The consequences of not reaching some threshold contribution reduce the incentive to deviate unilaterally, i.e. to free-ride on others' efforts. Coordination is harder under uncertainty because the number of equilibria is higher than under certainty and they are often close to each other in terms of expected payoffs. Hence, the disincentive to free-ride is smaller under uncertainty. Our experiment is arguably special in so far as it does not test a precise theory but rather whether groups are able to reach the payoffdominant equilibrium when they are many. Furthermore, unlike previous experimental studies, we increased uncertainty by adding some additional noise to the probability distribution that complicated players' expectations formation.

The experimental results show that threshold uncertainty negatively affected the provision of the public good. Whereas all our experimental groups succeeded in preventing the public bad when the threshold was known, this result was not replicated in presence of threshold uncertainty. Contributions were generally lower when players did not know the threshold precisely. Moreover, contributions were particularly low and erratic when players faced ambiguity.

The players' proposals for the targeted collective contribution indicate that ex-ante the players made similar plans in all treatments. However, in the presence of uncertainty (and in 
particular of ambiguity), contributions were markedly lower than proposals, arguably because players were more sensitive to others' behavior. This sensitivity did not matter so much when players got off on a good start of the game. However, there was also a tendency among players facing ambiguity to start the game "carefully" with relatively low first round contributions. The combination of both, the sensitivity and the slow start, eventually led to a very poor performance of some groups in these treatments. On the other hand, when a group happened to start the game with high and equally distributed first round contributions, it was likely to reach an overall high contribution level and to ultimately avert the collective damage. As a consequence the group performance varied widely under uncertainty. The key result of our experiment therefore is that early action and fairness become very important in the presence of uncertainty.

The finding that people who do not know the target with precision rely on other people in their peer group for guidance may help to explain the prominent role of equity and fairness in international agreements, such as climate agreements (Lange et al. 2007). However, unlike in our game, the fair distribution of efforts is not obvious as countries do not only differ in their contributions to global public goods but also in many other aspects. In addition to this comparability problem, countries' fairness perceptions are often subject to a self-serving bias so that they prefer the fairness principle that would generate least costs for them (Lange et al. 2010). Therefore, if a fair distribution is decisive for success but at the same time difficult to implement, a practical implication may be to reframe the negotiations in a way that makes the comparison easier (Barrett 2011a).

Another key result of the experiment is the $100 \%$ success rate under certainty and its robustness with respect to the distribution of efforts among players and over time. It suggests that, if the natural tipping points were known with precision and the consequences of 
triggering them were truly catastrophic, countries could be expected to tackle the problem. The large uncertainty involved in many natural systems, however, may worsen the chances considerably. Therefore our results accentuate the need for research to reduce environmental uncertainty. 


\section{References}

Alley, R. B., J. Marotzke, W. D. Nordhaus, J. T. Overpeck, D. M. Peteet, R. A. Pielke Jr., R. T. Pierrehumbert, P. B. Rhines, T. F. Stocker, L. D. Talley, and J. M. Wallace (2003), Abrupt Climate Change, Science 299 (5615), 2005-2010.

Bagnoli, M. and B. L. Lipman (1989), Provision of Public Goods: Fully Implementing the Core through Private Contributions, The Review of Economic Studies 56 (4), 583-601.

Bailey, R., J. Eichberger, and D. Kelsey (2005), Ambiguity and Public Good Provision in Large Societies, Journal of Public Economic Theory 7, 741-759.

Barrett, S. (2011a), Avoiding disastrous climate change is possible but not inevitable, Proceedings of the National Academy of Sciences 108 (29), 11733-11734.

Barrett, S. (2011b), Climate Treaties and Approaching Catastrophes, Columbia University, available at:

http://web.me.com/scottbarrett/scottbarrett.me.com/Climate_Change_files/Approachin g\%20Catastrophes\%20Full\%20Paper.pdf.

Budescu, D.V., A. Rapoport, and R. Suleiman (1990), Resource dilemmas with environmental uncertainty and asymmetric players, European Journal of Social Psychology 20, 475487.

Camerer, C. and M. Weber (1992), Recent developments in modeling preferences: Uncertainty and ambiguity, Journal of Risk and Uncertainty 5 (4), 325-370.

Chua Chow, C. and R. K. Sarin (2002), Known, Unknown, and Unknowable Uncertainties, Theory and Decision 52 (2), 127-138.

Croson, R. and M. Marks (2000), Step Returns in Threshold Public Goods: A Meta- and Experimental Analysis, Experimental Economics 2 (3), 239-259. 
Eichberger J. and D. Kelsey (2002), Strategic Complements, Substitutes and Ambiguity: The Implications for Public Goods, Journal of Economic Theory 106, 436-466.

Eichberger, J., D. Kelsey, and B. Schipper (2008), Granny versus Game Theorist: Ambiguity in Experimental Games, Theory and Decision 64, 333-362.

Ellsberg, D. (1961), Risk, Ambiguity, and the Savage Axioms, The Quarterly Journal of Economics 75 (4), 643-669.

Finus, M. (2001) Game Theory and International Environmental Cooperation, Edward Elgar, Cheltenham, UK.

Fischbacher, U. (2007), Z-Tree: Zurich Toolbox for Ready-made Economic Experiments, Experimental Economics 10 (2), 171-178.

Greiner, B. (2004), An Online Recruitment System for Economic Experiments, in: Kremer K. and V. Macho (Eds.), Forschung und wissenschaftliches Rechnen, GWDG Bericht 63, Gesellschaft für Wissenschaftliche Datenverarbeitung Göttingen, 79-93.

Gustafsson, M., A. Biel, and T. Gärling (1999), Overharvesting of resources of unknown size, Acta Psychologica 103 (1-2), 47-64.

Isaac, R. M., K. F. McCue, C. R. Plott (1985), Public Goods Provision in an Experimental Environment, Journal of Public Economics 26, 51-74.

Knight, F. H. (1921), Risk, Uncertainty, and Profit, Hart, Schaffner \& Marx, Houghton Mifflin Co., 1st Edition, Boston, MA.

Kontani, K., K. Tanaka, and S. Managi (2010), Cooperative choice and its framing effect under threshold uncertainty in a provision point mechanism, available at: http://ssrn.com/abstract=1616065. 
Kriegler, E., J. W. Hall, H. Hermann, R. Dawson, and H. J. Schellnhuber (2009), Imprecise probability assessment of tipping points in the climate system, Proceedings of the National Academy of Sciences 106 (13), 5041-5046.

Lange, A., C. Vogt, and A. Ziegler (2007), On the Importance of Equity in International Climate Policy: An Empirical Analysis, Energy Economics 29 (3), 545-562.

Lange, A., A. Löschel, C. Vogt, and A. Ziegler (2010), On the Self-Interested Use of Equity in International Climate Negotiations, European Economic Review 54 (3), 359-375.

Lenton, T. M., H. Held, E. Kriegler, J. W. Hall, W. Lucht, S. Rahmstorf, and H. J. Schellnhuber (2008), Tipping elements in the Earth's climate system, Proceedings of the National Academy of Sciences 105 (6), 1786-1793.

McBride, M. (2006), Discrete public goods under threshold uncertainty, Journal of Public Economics 90, 1181- 1199.

McBride, M. (2010), Threshold uncertainty in discrete public good games: an experimental study, Economics of Governance 11 (1), 77-99.

Milinski, M., R. D. Sommerfeld, H.-J. Krambeck, F. A. Reed, and J. Marotzke (2008), The collective-risk social dilemma and the prevention of simulated dangerous climate change, Proceedings of the National Academy of Sciences 105 (7), 2291-2294.

Nitzan, S. and R. E. Romano (1990), Private provision of a discrete public good with uncertain cost, Journal of Public Economics 42 (3), 357-370.

Palfrey T.R. and H. Rosenthal (1984), Participation and the Provision of Public Goods: A Strategic Analysis, Journal of Public Economics 24, 171-193. 
Rapoport, A., D.V. Budescu, R. Suleiman, and E. Weg (1992), Social dilemmas with uniformly distributed resources, in W.B.G. Liebrand et al. (Eds), Social dilemmas: Theoretical issues and research findings, Oxford, Pergamon Press, 43-57.

Rondeau, D., G. L. Poe, and W. D. Schulze (2005), VCM or PPM? A comparison of the performance of two voluntary public goods mechanisms, Journal of Public Economics $89(8), 1581-1592$.

Savage, L.J. (1954), The Foundations of Statistics, New York, Wiley.

Scheffer, M., S. Carpenter, J. A. Foley, C. Folke, and B. Walker (2001), Catastrophic shifts in ecosystems Nature, 413 (6856), 591-596.

Slovic, P. and A. Tversky (1974), Who Accepts Savage's Axiom?, Behavioral Science, 19, 368-373.

Spencer, M. A., S. K. Swallow, J. F. Shogren, and J. A. List (2009), Rebate rules in threshold public good provision, Journal of Public Economics 93 (5-6), 798-806.

Suleiman, R. (1997), Provision of Step-Level Public Goods under Uncertainty a Theoretical Analysis, Rationality and Society 9 (2), 163-187.

Suleiman, R., D. V. Budescu, and A. Rapoport (2001), Provision of Step-Level Public Goods with Uncertain Provision Threshold and Continuous Contribution, Group Decision and Negotiation 10 (3), 253-274.

Tavoni, A., A. Dannenberg, G. Kallis, and A. Löschel (2011), Inequality, communication and the avoidance of disastrous climate change in a public goods game, Proceedings of the National Academy of Sciences 108 (29), 11825-11829.

Wit, A. and H. Wilke (1998), Public good provision under environmental and social uncertainty, European Journal of Social Psychology 28 (2), 249-256. 
Table I: Experimental design

\begin{tabular}{c|c|c|c|c|c}
\hline Treatment & Uncertainty & Interval & Threshold & Probability & No. of subjects \\
\hline Baseline & None & {$[€ 0, € 240]$} & $\mathrm{T}=120$ & Known $(=1)$ & 60 \\
\hline Triangular & Risk & {$[€ 0, € 240]$} & $\mathrm{E}(\mathrm{T})=120$ & Known & 60 \\
\hline Uniform & Risk & {$[€ 0, € 240]$} & $\mathrm{E}(\mathrm{T})=120$ & Known & 60 \\
\hline AmbTriangular & Ambiguity & {$[€ 0, € 240]$} & & Unknown & 60 \\
\hline AmbUniform & Ambiguity & {$[€ 0, € 240]$} & & Unknown & 60 \\
\hline
\end{tabular}

Table II: Expected payoffs

\begin{tabular}{c|c|c|c|c|c|c}
\hline Treatment & $\begin{array}{c}\pi(0) \\
(I=0)\end{array}$ & $\begin{array}{c}\pi(20) \\
(I=120)\end{array}$ & $\begin{array}{c}\pi(40) \\
(I=240)\end{array}$ & $c^{*}$ & $\pi\left(c^{*}\right)$ & $I^{*}$ \\
\hline Baseline & 4.0 & 20.0 & 0 & 20 & 20.0 & 120 \\
\hline Triangular & 4.7 & 12.3 & 0 & 20 & 12.3 & 120 \\
\hline Uniform & 6.8 & 11.7 & 0 & 17 & 12.0 & 100 \\
\hline
\end{tabular}

Note: Player's expected payoffs from following a symmetric strategy and from the collectively optimal cumulative investment $c^{*}$. If all players contribute an equal share of the burden $(c=20)$, this corresponds to an expected payoff of $€ 20$ in Baseline and $€ 12.3$ in Triangular. In Uniform, players are best off when each provides about $€ 17$, which is not possible given that in each round the strategy set is $C=\{0,2,4\}$. Of course players could still coordinate on $I^{*}=100$, but that necessarily requires asymmetric contributions.

Table III: Summary statistics

\begin{tabular}{c|c|c|c|c}
\hline Treatment & $\begin{array}{c}\text { First } \\
\text { proposal }\end{array}$ & $\begin{array}{c}\text { Second } \\
\text { proposal }\end{array}$ & $\begin{array}{c}\text { Group } \\
\text { contribution }\end{array}$ & $\begin{array}{c}\text { Min / max group } \\
\text { contribution }\end{array}$ \\
\hline Baseline & $\begin{array}{c}121.8 \\
(9.1)\end{array}$ & $\begin{array}{c}121.9 \\
(4.4)\end{array}$ & $\begin{array}{c}121.2 \\
(2.1)\end{array}$ & $120 / 126$ \\
\hline Triangular & $\begin{array}{l}120.4 \\
(19.4)\end{array}$ & $\begin{array}{c}122.9 \\
(19.8)\end{array}$ & $\begin{array}{c}99.4 \\
(20.4)\end{array}$ & $78 / 140$ \\
\hline Uniform & $\begin{array}{l}124.1 \\
(10.6)\end{array}$ & $\begin{array}{c}123.2 \\
(12.4)\end{array}$ & $\begin{array}{c}101.4 \\
(19.5)\end{array}$ & $58 / 122$ \\
\hline AmbTriangular & $\begin{array}{c}127.0 \\
(7.5)\end{array}$ & $\begin{array}{c}120.3 \\
(9.8)\end{array}$ & $\begin{array}{c}84.0 \\
(24.6)\end{array}$ & $36 / 120$ \\
\hline AmbUniform & $\begin{array}{c}122.9 \\
(12.8)\end{array}$ & $\begin{array}{c}115.2 \\
(16.8)\end{array}$ & $\begin{array}{c}83.0 \\
(30.7)\end{array}$ & $26 / 118$ \\
\hline Note: Average
\end{tabular}

Note: Average values by treatment; standard deviations in parentheses; last column shows the minimum and maximum group contributions. 
Table IV: Significance of treatment differences

\begin{tabular}{|c|c|c|c|c|}
\hline Triangular & 0.0043 & & & \\
\hline Uniform & $\begin{array}{c}0.0023 \\
(0.0026)\end{array}$ & $\begin{array}{c}0.4717 \\
(0.7305)\end{array}$ & & \\
\hline AmbTriangular & $\begin{array}{c}0.0003 \\
(0.0041)\end{array}$ & $\begin{array}{c}0.1032 \\
(0.8030)\end{array}$ & $\begin{array}{c}0.0819 \\
(0.6027)\end{array}$ & \\
\hline \multirow[t]{2}{*}{ AmbUniform } & $\begin{array}{c}0.0001 \\
(0.0000)\end{array}$ & $\begin{array}{c}0.2727 \\
(0.1162)\end{array}$ & $\begin{array}{c}0.1854 \\
(0.0742) \\
\end{array}$ & $\begin{array}{c}0.8501 \\
(0.2596)\end{array}$ \\
\hline & Baseline & Triangular & Uniform & AmbTriangular \\
\hline
\end{tabular}

Note: p-values from a Wilcoxon rank-sum test of treatment differences in average contributions; in parentheses p-values from a Levene test of treatment differences in variances.

Table V: Success rate at given hypothetical thresholds

\begin{tabular}{c|c|c|c|c|c}
\hline Threshold & Baseline & Triangular & Uniform & AmbTriangular & AmbUniform \\
\hline 20 & & $100 \%$ & $100 \%$ & $100 \%$ & $100 \%$ \\
\hline 40 & & $100 \%$ & $100 \%$ & $90 \%$ & $90 \%$ \\
\hline 60 & & $100 \%$ & $90 \%$ & $90 \%$ & $80 \%$ \\
\hline 80 & & $90 \%$ & $90 \%$ & $50 \%$ & $60 \%$ \\
\hline 100 & & $40 \%$ & $60 \%$ & $20 \%$ & $40 \%$ \\
\hline 120 & $100 \%$ & $20 \%$ & $20 \%$ & $10 \%$ & $0 \%$ \\
\hline 140 & & $10 \%$ & $0 \%$ & $0 \%$ & $0 \%$ \\
\hline 160 & & $0 \%$ & $0 \%$ & $0 \%$ & $0 \%$ \\
\hline
\end{tabular}

Note: Percentage of groups which would have reached hypothetical thresholds given the actual amounts contributed in the game. 
Table VI: Linear regression of group investment

\begin{tabular}{|c|c|c|c|c|}
\hline Variables & $\begin{array}{c}(1) \\
\text { Rd.1-10 }\end{array}$ & $\begin{array}{c}(2) \\
\text { Rd.1-10 }\end{array}$ & $\begin{array}{c}(3) \\
\text { Rd.2-10 }\end{array}$ & $\begin{array}{c}(4) \\
\text { Rd.2-10 }\end{array}$ \\
\hline \multicolumn{5}{|c|}{$\begin{array}{l}\text { Treatment dummies } \\
\text { (Reference: Baseline or Triangular) }\end{array}$} \\
\hline Triangular & $\begin{array}{l}-9.158 \\
(6.695)\end{array}$ & & $\begin{array}{l}-6.665 \\
(6.496)\end{array}$ & \\
\hline Uniform & $\begin{array}{c}-16.39 * * * \\
(4.821)\end{array}$ & $\begin{array}{l}-6.943 \\
(5.638)\end{array}$ & $\begin{array}{c}-13.14 * * \\
(5.140)\end{array}$ & $\begin{array}{l}-6.499 \\
(4.663)\end{array}$ \\
\hline AmbTriangular & $\begin{array}{c}-21.19 * * * \\
(7.250)\end{array}$ & $\begin{array}{c}-11.38 * * \\
(5.517)\end{array}$ & $\begin{array}{c}-15.22 * * \\
(6.702)\end{array}$ & $\begin{array}{c}-6.948 \\
(4.262)\end{array}$ \\
\hline AmbUniform & $\begin{array}{c}-24.22 * * * \\
(6.196)\end{array}$ & $\begin{array}{c}-13.38 * * \\
(5.788)\end{array}$ & $\begin{array}{c}-19.06 * * * \\
(6.470)\end{array}$ & $\begin{array}{c}-10.21 * \\
(5.403)\end{array}$ \\
\hline Average 1st proposal & $\begin{array}{l}0.0848 \\
(0.176)\end{array}$ & $\begin{array}{l}0.0665 \\
(0.234)\end{array}$ & $\begin{array}{c}0.120 \\
(0.171)\end{array}$ & $\begin{array}{c}0.268 \\
(0.207)\end{array}$ \\
\hline Average 2nd proposal & $\begin{array}{c}0.764 * * * \\
(0.198)\end{array}$ & $\begin{array}{c}0.764 * * * \\
(0.230)\end{array}$ & $\begin{array}{c}0.637 * * * \\
(0.163)\end{array}$ & $\begin{array}{c}0.466 * * \\
(0.192)\end{array}$ \\
\hline Group investment rd.1 & & & $\begin{array}{c}1.160 \\
(0.839)\end{array}$ & $\begin{array}{c}2.127^{* *} * \\
(0.939)\end{array}$ \\
\hline \multicolumn{5}{|c|}{$\begin{array}{l}\text { Motivation investment } \\
\text { (no. of group members, reference: risk assessment) }\end{array}$} \\
\hline Own proposal & $\begin{array}{c}4.075 * * * \\
(1.366)\end{array}$ & $\begin{array}{l}4.968 * * \\
(2.100)\end{array}$ & $\begin{array}{l}2.712 * \\
(1.397)\end{array}$ & $\begin{array}{l}2.933 \\
(2.087)\end{array}$ \\
\hline Average proposal & $\begin{array}{l}8.968 * * * \\
(2.025)\end{array}$ & $\begin{array}{c}9.082 * * * \\
(2.192)\end{array}$ & $\begin{array}{c}6.293 * * * \\
(1.953)\end{array}$ & $\begin{array}{c}5.759 * * * \\
(1.894)\end{array}$ \\
\hline Safety & $\begin{array}{c}2.771 \\
(1.908)\end{array}$ & $\begin{array}{c}4.598 \\
(3.229)\end{array}$ & $\begin{array}{c}3.040 \\
(1.958)\end{array}$ & $\begin{array}{c}7.109 * * \\
(3.436)\end{array}$ \\
\hline \multicolumn{5}{|c|}{$\begin{array}{l}\text { Fairness } \\
\text { (no. of group members, reference: no fairness) }\end{array}$} \\
\hline Positive & $\begin{array}{c}-0.112 \\
(1.365)\end{array}$ & $\begin{array}{c}0.619 \\
(1.976)\end{array}$ & $\begin{array}{c}0.111 \\
(1.192)\end{array}$ & $\begin{array}{c}1.719 \\
(1.706)\end{array}$ \\
\hline Negative & $\begin{array}{c}-5.270 * * \\
(2.368)\end{array}$ & $\begin{array}{l}-5.122 * \\
(2.571)\end{array}$ & $\begin{array}{c}-5.532 * * * \\
(2.009)\end{array}$ & $\begin{array}{c}-5.249 * * \\
(2.181)\end{array}$ \\
\hline Constant & $\begin{array}{l}-1.499 \\
(21.10)\end{array}$ & $\begin{array}{l}-12.76 \\
(25.26)\end{array}$ & $\begin{array}{l}-12.02 \\
(19.61)\end{array}$ & $\begin{array}{c}-31.74 \\
(25.21)\end{array}$ \\
\hline $\begin{array}{l}\text { No. of observations } \\
R^{2}\end{array}$ & 50 & 40 & 50 & 40 \\
\hline$\underline{\mathrm{R}^{2}}$ & 0.856 & 0.825 & 0.862 & 0.846 \\
\hline
\end{tabular}


Figure 1: The distribution of balls used to determine the threshold
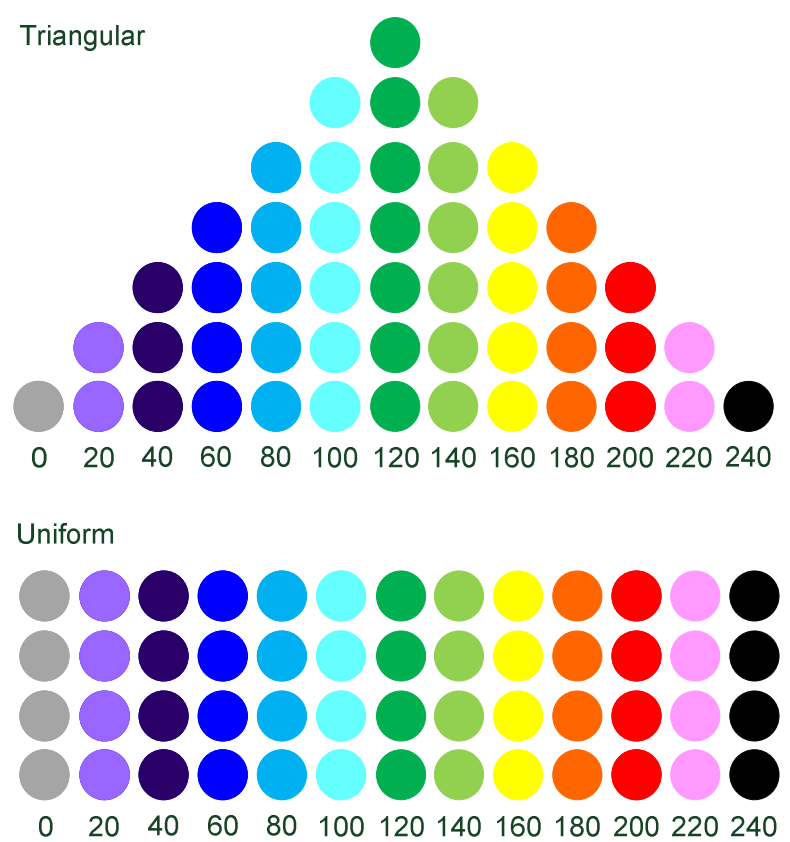

AmbTriangular
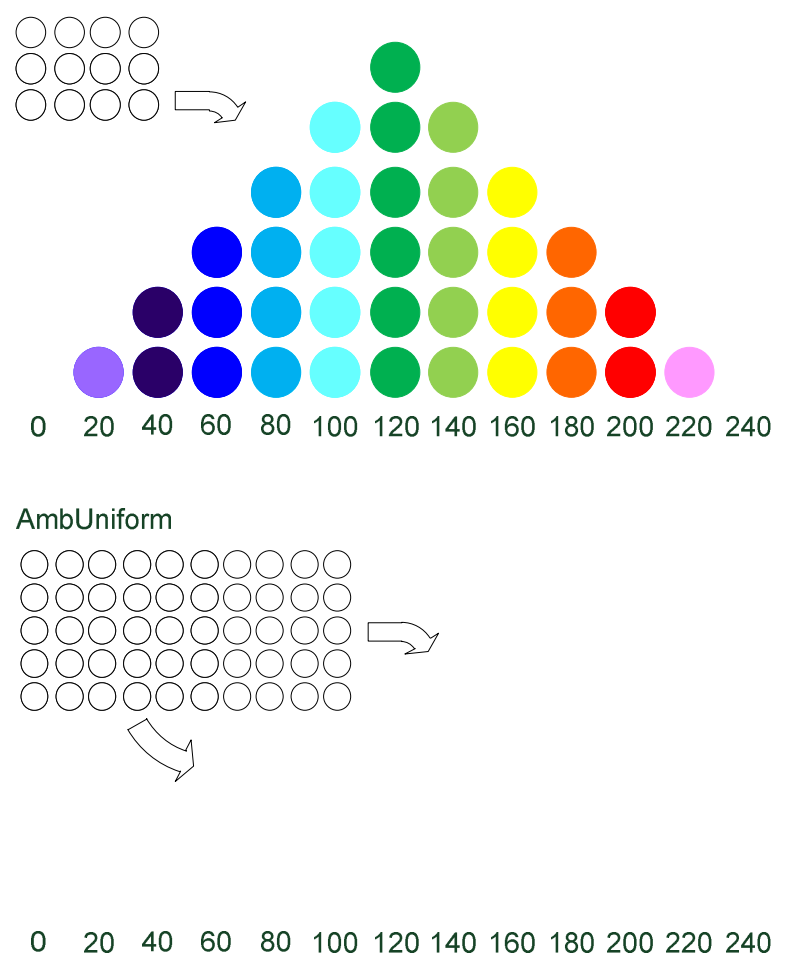
Figure 2: The provision probability for each threshold

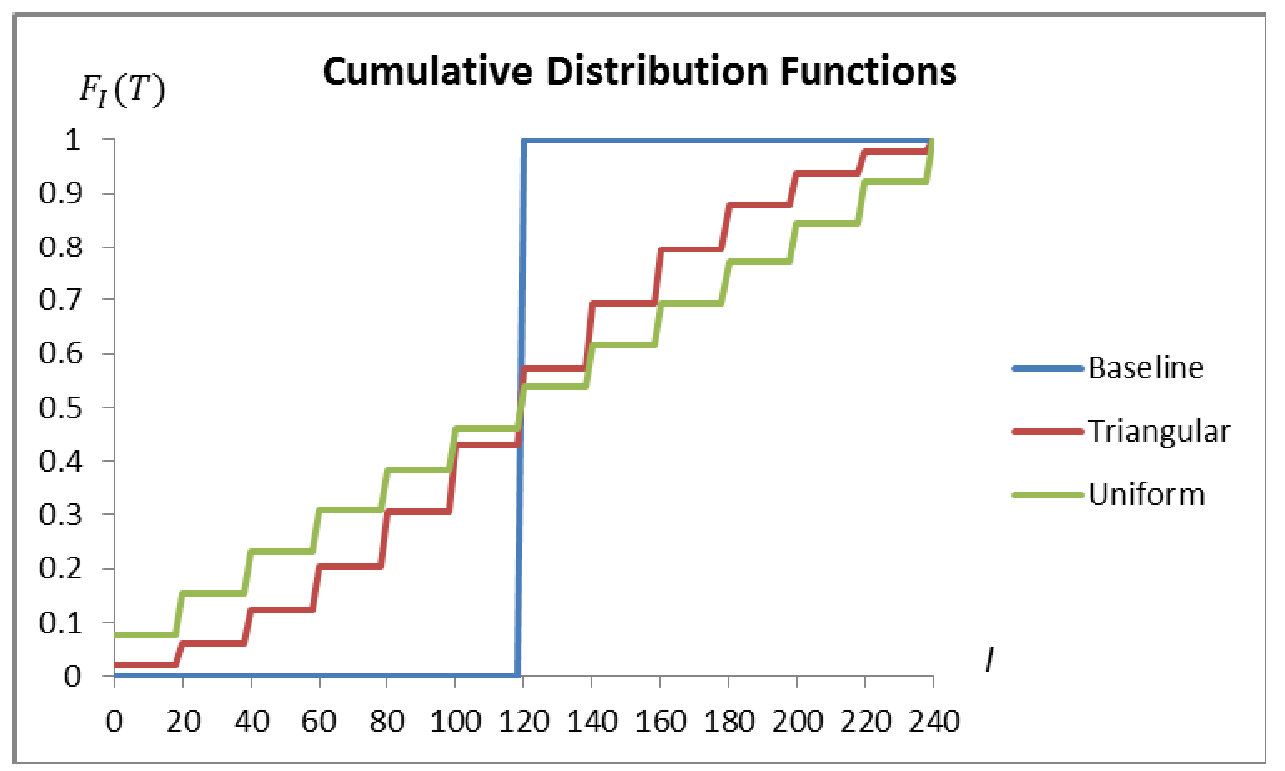

Figure 3: Costs and benefits from contributing to the public good

(the black line indicates the maximum expected payoff achievable by a group)

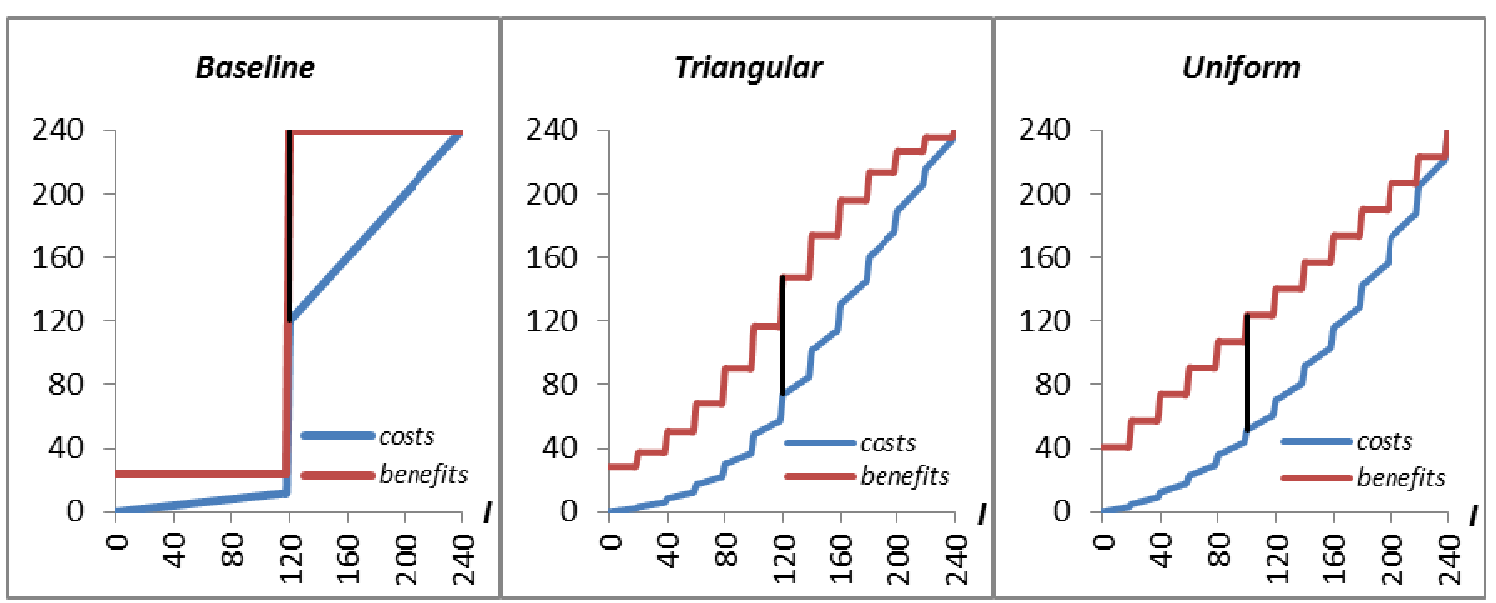


Figure 4

Proposals and contributions
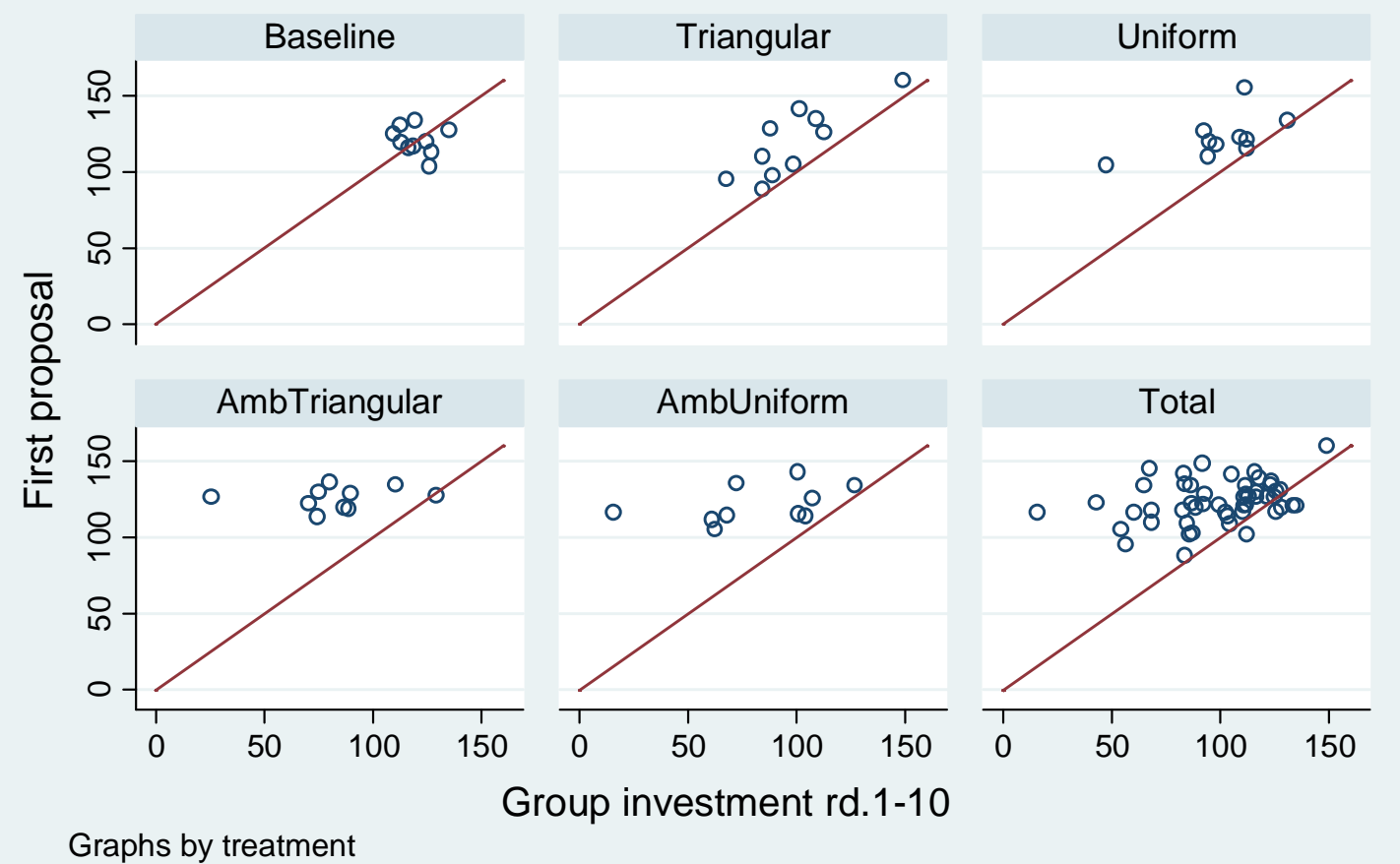

Graphs by treatment
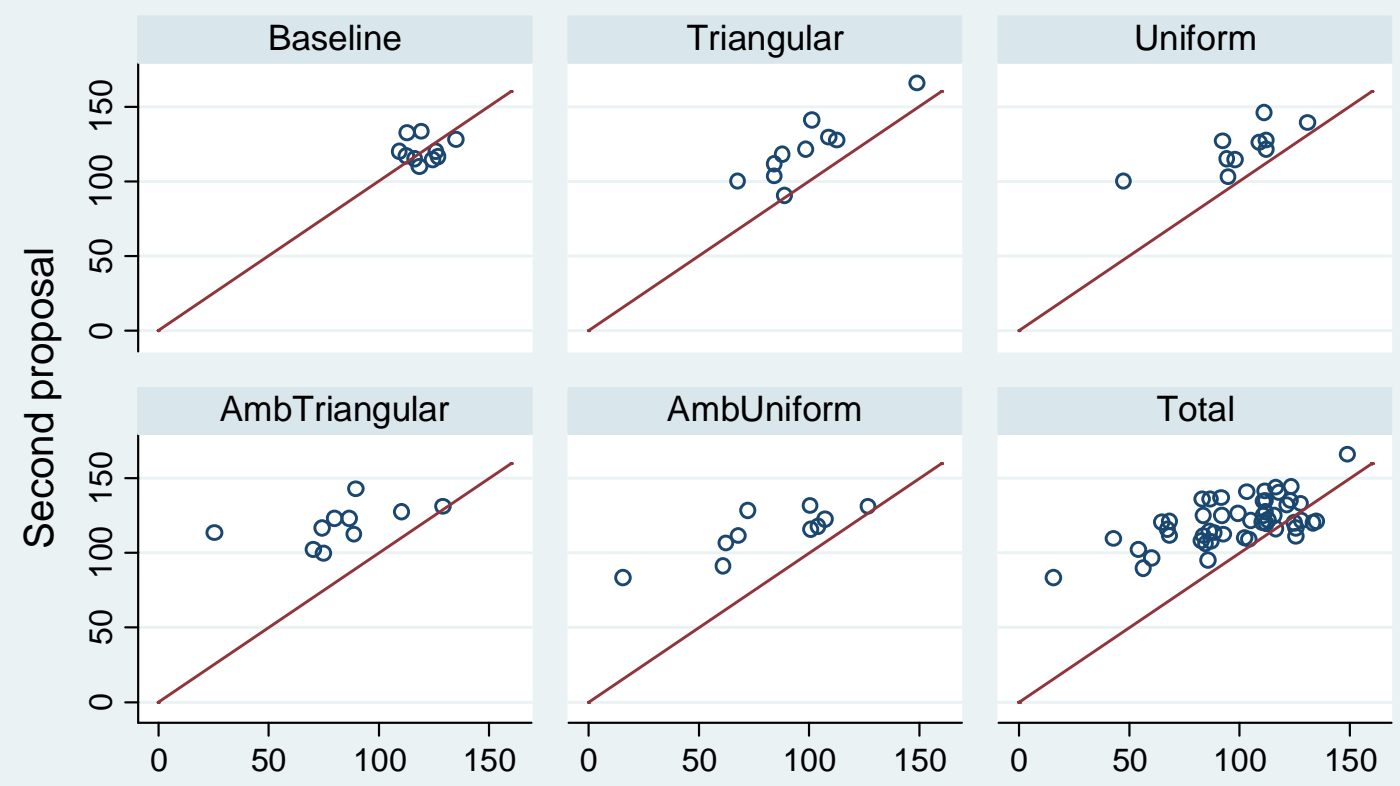

Group investment rd.1-10

Graphs by treatment

Correlation between average proposals and investment 

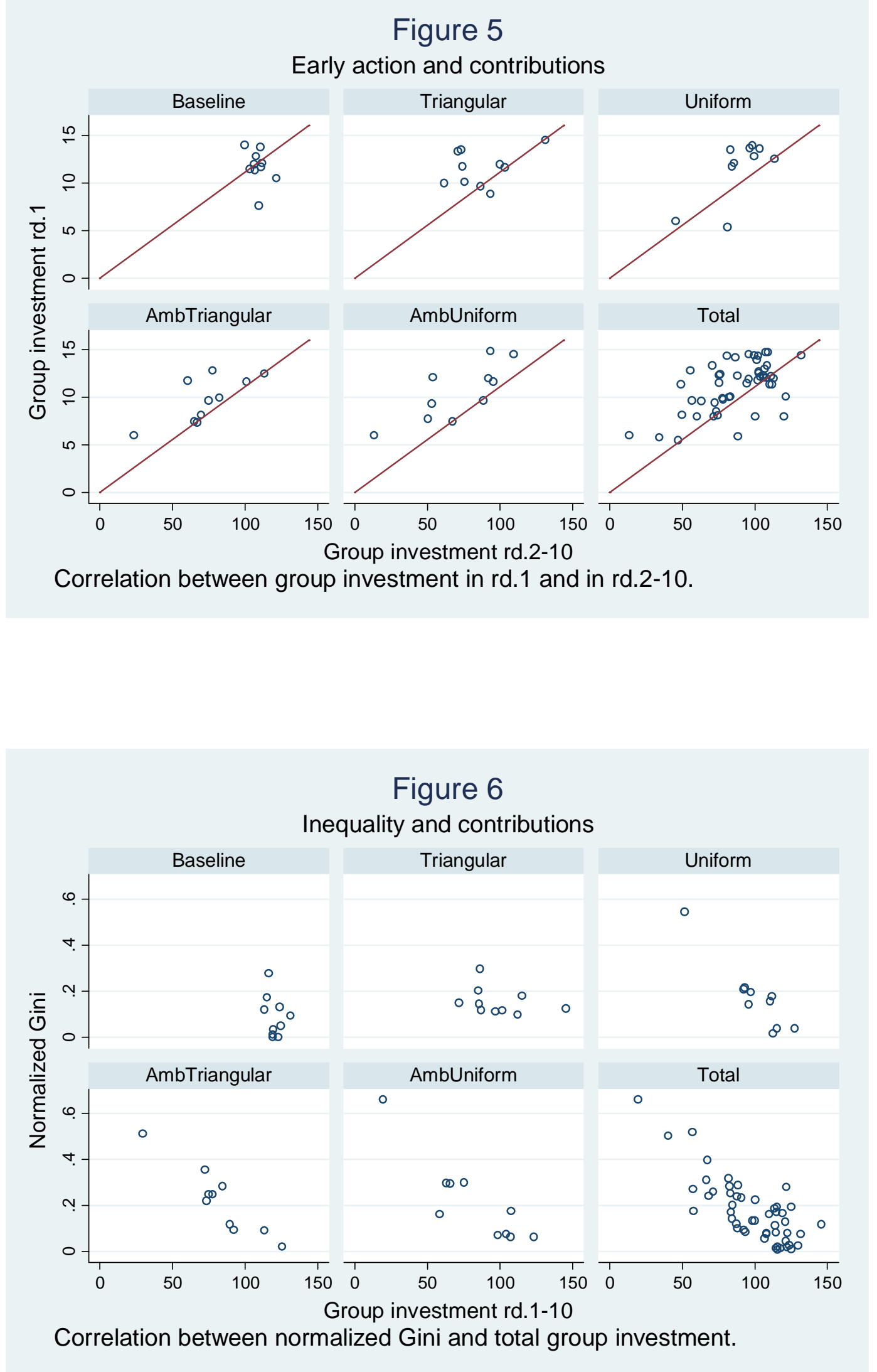


\section{Appendix}

\section{Supporting Theoretical Analyses}

\section{Table SI: Example I}

\begin{tabular}{|c|c|c|c|c|c|c|}
\hline Round & $\mathrm{P} 1$ & $\mathrm{P} 2$ & $\mathrm{P} 3$ & $\mathrm{P} 4$ & P5 & $\mathrm{P} 6$ \\
\hline 1 & 2 & 2 & 2 & 2 & 2 & 2 \\
\hline 2 & 2 & 2 & 2 & 2 & 2 & 2 \\
\hline 3 & 2 & 2 & 2 & 2 & 2 & 2 \\
\hline 4 & 2 & 2 & 2 & 2 & 2 & 2 \\
\hline 5 & 2 & 2 & 2 & 2 & 2 & 2 \\
\hline 6 & 2 & 2 & 2 & 2 & 2 & 2 \\
\hline 7 & 2 & 2 & 2 & 2 & 2 & 2 \\
\hline 8 & 2 & 2 & 2 & 2 & 2 & 2 \\
\hline 9 & 2 & 2 & 2 & 2 & 2 & 2 \\
\hline 10 & 2 & 2 & 2 & 2 & 2 & 2 \\
\hline
\end{tabular}

Note: An hypothetical example of symmetrical play of the $C=2$ strategy in Uniform; $I=120$ is a Nash equilibrium, as switching to $C=0$ in the last round diminishes the expected value.

Table SII: Example II

\begin{tabular}{|c|c|c|c|c|c|c|}
\hline Round & P1 & $\mathrm{P} 2$ & P3 & P4 & P5 & P6 \\
\hline 1 & 4 & 4 & 4 & 4 & 4 & 4 \\
\hline 2 & 4 & 4 & 4 & 4 & 2 & 2 \\
\hline 3 & 2 & 2 & 2 & 2 & 2 & 2 \\
\hline 4 & 2 & 2 & 2 & 2 & 2 & 2 \\
\hline 5 & 2 & 2 & 2 & 2 & 2 & 2 \\
\hline 6 & 2 & 2 & 2 & 2 & 2 & 2 \\
\hline 7 & 2 & 2 & 2 & 2 & 2 & 2 \\
\hline 8 & 2 & 2 & 2 & 2 & 2 & 2 \\
\hline 9 & 2 & 2 & 2 & 2 & 2 & 2 \\
\hline 10 & 2 & 2 & 2 & 2 & 2 & 2 \\
\hline
\end{tabular}

Note: An hypothetical example showing that $I=140$ is not supportable as a Nash equilibrium in Uniform; switching to $C=0$ in the last round is a profitable deviation.

Tables SI and SII present hypothetical examples for the Uniform treatment. The example in Table SI shows that, given the symmetric intermediate-contribution strategies followed by all players in rounds $1-9$, no one has an incentive to deviate in the final round. By sticking to $C=2$, players expect $\pi=€ 11.7$, while if a single player switches to $C=0$, the expected 
payoff from $T=100$ is $€ 11.3 .{ }^{10}$ Having established that $T=120$ is (under reasonable symmetrical contributions conditions) preferred to $T=100$, we show in Table SII that $T=140$ is not preferred to $T=120$. Assume that players $1-4$ have each invested $€ 22$ in the first 9 rounds, while players 5-6 have each invested $€ 20$. This means they have collectively contributed $€ 128$ to the climate account, before the last round begins: are they better off by all choosing $C=2$ in round 10 and reaching $T=140$ ? Players 5 and 6 would, as the ensuing expected pay is $€ 11.8$, while switching to $C=0$ implies an expected pay of $€ 11.7$. However, this is not a Nash equilibrium, as players 1-4 are (marginally) better off when switching from $C=2$ to $C=0(€ 10.46<€ 10.52)$.

\footnotetext{
${ }^{10}$ Note that, should a player (irrationally) deviate in round 10 and choose $C=0$, the remaining players would be best-off by following suit, as $\pi(22)=€ 10.5<\pi(18)=€ 11.3$. That is, it is not advantageous for other players to compensate the free-rider, so $T=120$ will not be provided. Put differently, the set of strategies requiring all an investment of $€ 2 /$ round is a Nash equilibrium, but is not evolutionarily stable. By contrast, $I=0$ (which doesn't require coordination) is always stable, so a deviating player will find it optimal to revert back to $C=0$ in successive rounds.
} 


\section{Supporting Empirical Analyses}

Table SIII: Ex-post questionnaire and responses

\begin{tabular}{|c|c|c|c|}
\hline Question & Answer & No. & $\%$ \\
\hline \multirow{4}{*}{$\begin{array}{l}\text { (1) What was the motivation for your first proposal for } \\
\text { the group target? Please tick one answer. }\end{array}$} & Safety & 81 & 27.00 \\
\hline & Risk assessment & 140 & 46.67 \\
\hline & Strategic considerations & 58 & 19.33 \\
\hline & Other & 21 & 7.00 \\
\hline \multirow{4}{*}{$\begin{array}{l}\text { (2) What was the motivation for your second proposal for } \\
\text { the group target? Please tick one answer. }\end{array}$} & Safety & 64 & 21.33 \\
\hline & Risk assessment & 127 & 42.33 \\
\hline & Strategic considerations & 82 & 27.33 \\
\hline & Other & 27 & 9.00 \\
\hline \multirow{5}{*}{$\begin{array}{l}\text { (3) Please recall your investment decisions during the } \\
\text { game. What was the motivation for your investment? } \\
\text { Please tick one answer. }\end{array}$} & Own proposal for group target & 86 & 28.67 \\
\hline & Average proposal for group target & 68 & 22.67 \\
\hline & Safety & 28 & 9.33 \\
\hline & Risk assessment & 79 & 26.33 \\
\hline & Other & 39 & 13.00 \\
\hline \multirow{4}{*}{$\begin{array}{l}\text { (4) Did fairness play a role in your investment decisions } \\
\text { and if so, in which respect? Please tick one answer. }\end{array}$} & Fairness did not play a role & 112 & 37.33 \\
\hline & $\begin{array}{l}\text { I invested more than initially } \\
\text { planned because my co-players } \\
\text { invested a lot }\end{array}$ & 17 & 5.67 \\
\hline & $\begin{array}{l}\text { I invested less than initially planned } \\
\text { because my co-players invested } \\
\text { little }\end{array}$ & 92 & 30.67 \\
\hline & Other fairness consideration & 79 & 26.33 \\
\hline \multirow{6}{*}{$\begin{array}{l}\text { (5) How do you see yourself: Are you generally a person } \\
\text { who is fully prepared to take risk or do you try to avoid } \\
\text { taking risk? Please tick a box on the scale, where the } \\
\text { value } 1 \text { means: "fully prepared to take risk" and the value } \\
6 \text { means: "risk averse". You can use the values in } \\
\text { between to make your estimate. }\end{array}$} & 1 (fully prepared to take risk) & 2 & 0.67 \\
\hline & 2 & 32 & 10.67 \\
\hline & 3 & 111 & 37.00 \\
\hline & 4 & 109 & 36.33 \\
\hline & 5 & 43 & 14.33 \\
\hline & 6 (risk averse) & 3 & 1 \\
\hline (6) How good are you at working with fractions (e.g. & 1 (not good at all) & 1 & 0.33 \\
\hline "one fifth of something") or percentages (e.g. " $20 \%$ of & 2 & 10 & 3.33 \\
\hline something")? Please tick a box on the scale, where the & 3 & 21 & 7.00 \\
\hline value 1 means: "not good at all" and the value 6 means: & 4 & 50 & 16.67 \\
\hline \multirow{2}{*}{$\begin{array}{l}\text { "extremely good". You can use the values in between to } \\
\text { make your estimate. }\end{array}$} & 5 & 123 & 41.00 \\
\hline & 6 (extremely good) & 95 & 31.67 \\
\hline (7) Generally speaking, would you say that most people & 1 (most people can be trusted) & 4 & 1.33 \\
\hline can be trusted or that you need to be very careful in & 2 & 28 & 9.33 \\
\hline dealing with people? Please tick a box on the scale, & 3 & 86 & 28.67 \\
\hline where the value 1 means: "most people can be trusted" & 4 & 94 & 31.33 \\
\hline and the value 6 means: "need to be very careful". You & 5 & 63 & 21.00 \\
\hline can use the values in between to make your estimate. & 6 (need to be very careful) & 25 & 8.33 \\
\hline \multirow{5}{*}{$\begin{array}{l}\text { (8) Do you trust your fellow students completely, } \\
\text { somewhat, not very much or not at all? Please tick one } \\
\text { answer. }\end{array}$} & Completely & 27 & 9.00 \\
\hline & Somewhat & 202 & 67.33 \\
\hline & Not very much & 63 & 21.00 \\
\hline & Not at all & 8 & 2.67 \\
\hline & & 300 & 100.00 \\
\hline
\end{tabular}

Table SIII presents the questions and responses from the ex-post questionnaire. It reveals that risk assessment was an important motivation for most players' proposal for the group target, while the motivation for the investment was more evenly distributed across different possibilities. For the majority of players fairness either did not play a role in their contribution 
decision or affected contributions negatively.

Table SIV: Linear regression of individual investment

\begin{tabular}{|c|c|c|}
\hline Variables & $\begin{array}{c}(1) \\
\text { Rd.1-10 }\end{array}$ & $\begin{array}{c}(2) \\
\text { Rd.1-10 }\end{array}$ \\
\hline \multicolumn{3}{|c|}{$\begin{array}{l}\text { Treatment dummies } \\
\text { (Reference: Baseline or Triangular) }\end{array}$} \\
\hline Triangular & $\begin{array}{l}-2.256 * * * \\
(0.662)\end{array}$ & \\
\hline Uniform & $\begin{array}{c}-2.032 * * * \\
(0.627)\end{array}$ & $\begin{array}{c}0.226 \\
(0.667)\end{array}$ \\
\hline AmbTriangular & $\begin{array}{c}-3.777 * * * \\
(0.953)\end{array}$ & $\begin{array}{l}-1.400 \\
(0.840)\end{array}$ \\
\hline AmbUniform & $\begin{array}{c}-3.672 * * * \\
(0.926)\end{array}$ & $\begin{array}{l}-1.306 \\
(0.874)\end{array}$ \\
\hline 1st proposal & $\begin{array}{l}0.00904 \\
(0.0138)\end{array}$ & $\begin{array}{c}0.0221 \\
(0.0135)\end{array}$ \\
\hline 2nd proposal & $\begin{array}{c}0.0760 * * * \\
(0.0140)\end{array}$ & $\begin{array}{c}0.0627 * * * \\
(0.0146)\end{array}$ \\
\hline Others average rd.1 & $\begin{array}{l}1.842 * * \\
(0.800)\end{array}$ & $\begin{array}{l}2.228 * * \\
(0.829)\end{array}$ \\
\hline \multicolumn{3}{|c|}{$\begin{array}{l}\text { Motivation 1st proposal } \\
\text { (Reference: risk assessment) }\end{array}$} \\
\hline Safety & $\begin{array}{l}1.005^{*} \\
(0.511)\end{array}$ & $\begin{array}{l}1.406^{* *} \\
(0.682)\end{array}$ \\
\hline Strategic & $\begin{array}{c}-1.726 * * \\
(0.722)\end{array}$ & $\begin{array}{l}-1.964 * * \\
(0.851)\end{array}$ \\
\hline \multicolumn{3}{|c|}{$\begin{array}{l}\text { Motivation investment } \\
\text { (Reference: risk assessment) }\end{array}$} \\
\hline Own proposal & $\begin{array}{l}3.974 * * * \\
(0.599)\end{array}$ & $\begin{array}{c}4.449 * * * \\
(0.649)\end{array}$ \\
\hline Average proposal & $\begin{array}{l}3.848 * * * \\
(0.724)\end{array}$ & $\begin{array}{c}4.279 * * * \\
(0.779)\end{array}$ \\
\hline Safety & $\begin{array}{l}3.590 * * * \\
(0.838)\end{array}$ & $\begin{array}{c}4.898 * * * \\
(1.333)\end{array}$ \\
\hline \multicolumn{3}{|c|}{$\begin{array}{l}\text { Fairness } \\
\text { (Reference: no fairness) }\end{array}$} \\
\hline Positive & $\begin{array}{c}2.536 * * * \\
(0.672)\end{array}$ & $\begin{array}{l}3.377 * * * \\
(0.851)\end{array}$ \\
\hline Negative & $\begin{array}{l}-0.0622 \\
(0.753)\end{array}$ & $\begin{array}{l}0.0316 \\
(0.815)\end{array}$ \\
\hline Constant & $\begin{array}{c}1.887 \\
(2.309) \\
\end{array}$ & $\begin{array}{l}-1.736 \\
(2.315) \\
\end{array}$ \\
\hline No. of observations & 300 & 240 \\
\hline $\mathrm{R}^{2}$ & 0.506 & 0.507 \\
\hline
\end{tabular}

Table SIV presents the results from a series of linear regressions of the cumulative individual contributions to the public good. Overall, the regression results confirm the key findings 
presented in the paper. First of all, the results confirm that uncertainty was detrimental for the willingness to cooperate. The subjects in Baseline contributed significantly more than the subjects in all the other treatments. The results confirm furthermore that a high first round contribution of the other fellow group members increased the individual investment. This effect is larger if the analysis is restricted to the uncertainty treatments. The players who made a larger second proposal chose somewhat larger contributions afterwards. This effect is not observed for the first proposal. On the other hand, the regression models show that players' motivation for their first proposals played an important role. The subjects who stated safety as most important motive for their proposal invested significantly more than those who stated risk assessment. The players whose proposals were subject to strategic considerations invested less. These differences explain why the first proposals and actual contributions did not necessarily go hand in hand. The regressions include also the motivation for the players' investment decisions. The players reporting own proposal, average proposal of the group, or safety to be the most important motive invested significantly more than the players whose decisions were mostly driven by the weighting of risk. Not surprisingly, the subjects who stated that fairness had a positive effect contributed more than the subjects who said that fairness had a negative effect and the subjects who decided without considering fairness. 


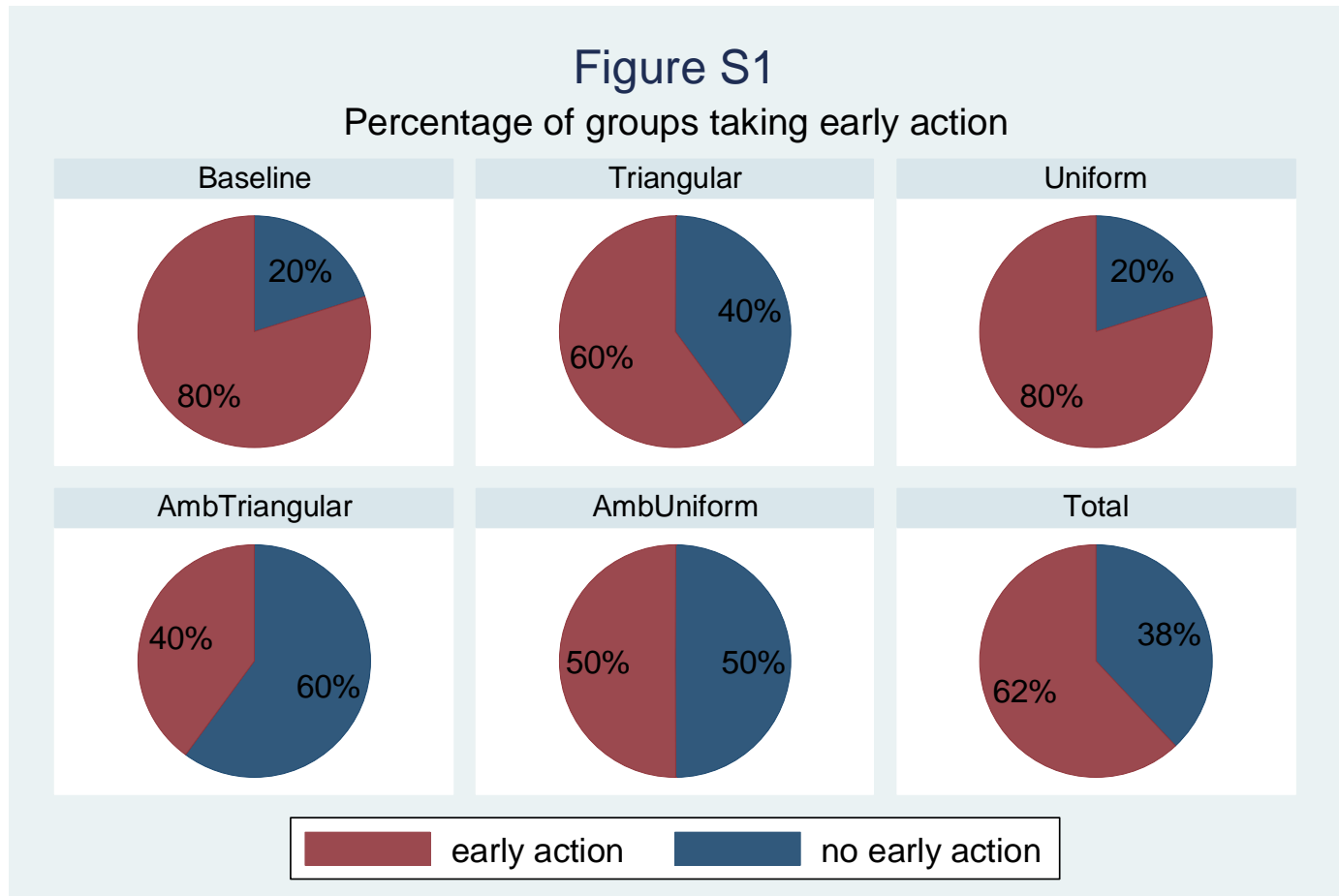

Early action defined as group investment in the first round being $€ 12$ or higher.

Figure S1 shows the percentage of groups taking early action, defined here as investing at least $€ 12$ in the first round. Baseline and Uniform are characterized by a high percentage of groups taking early action ( $80 \%$ each). Relatively few groups took early action in Triangular (60\%), AmbTriangular (40\%), and AmbUniform (50\%). 


\section{Supporting Material}

Experimental Instructions (Triangular treatment)

Welcome to our experiment!

\section{General information}

In our experiment, you can earn money. How much you earn depends on the gameplay, or more precisely on the decisions you and your fellow players make. Regardless of the gameplay, you will receive $€ 2$ for your participation. For a successful run of this experiment, it is absolutely necessary that you do not talk to other participants or do not communicate in any other way. Now read the following rules of the game carefully. If you have any questions, please give us a hand signal. It is important that you read up to the STOP sign only. Please wait when you get there, as we will give you a brief oral explanation before we continue.

\section{Game rules}

There are six players in the game, meaning you and five other players. Each player is faced with the same decision problem. In the beginning of the experiment, you receive a starting capital of $€ 40$, which is credited to your personal account. During the experiment, you can use the money in your account or let it be. In the end, your current account balance is paid to you in cash. Your decisions are anonymous. For the purpose of anonymity, you will be allocated a pseudonym which will be used for the whole duration of the game. You can see your pseudonym in the lower left corner of your display.

The experiment has exactly ten rounds. In each round, you can invest your money in order to try and prevent damage. The damage will have a considerable negative financial impact on all 
players. In each round of the game, all six players are asked the following question at the same time:

\section{"How much do you want to invest to prevent damage?"}

You can answer with €0, €2 or €4. After each player has made her or his decision, the six decisions are displayed at the same time. After that, all money paid by the players is booked to a special account for damage prevention.

At the end of the game (after exactly ten rounds), the computer calculates the total investments made by all players. If the investments have reached a certain minimum, the damage is prevented. In this case, each player is paid the money remaining in her or his account, meaning the $€ 40$ starting capital minus the money the player has invested in preventing damage over the course of the game. However, if the total investments are lower than the minimum, the damage occurs: All players lose $90 \%$ of the remaining money in their personal accounts. The minimum to be reached in order to prevent damage will be drawn randomly. We will draw the minimum after the game in your presence. The draw goes like this: The minimum can take the values $0,20,40,60$ etc. up to 240 (always in steps of 20). For each of these 13 values, a certain number of balls in different colors is put into a bag. One ball is drawn from the bag and the value shown on the ball is the minimum value for the game. The following figure shows the distribution of the different balls. There are 49 balls altogether. These balls are put into a bag, and one is drawn randomly. 


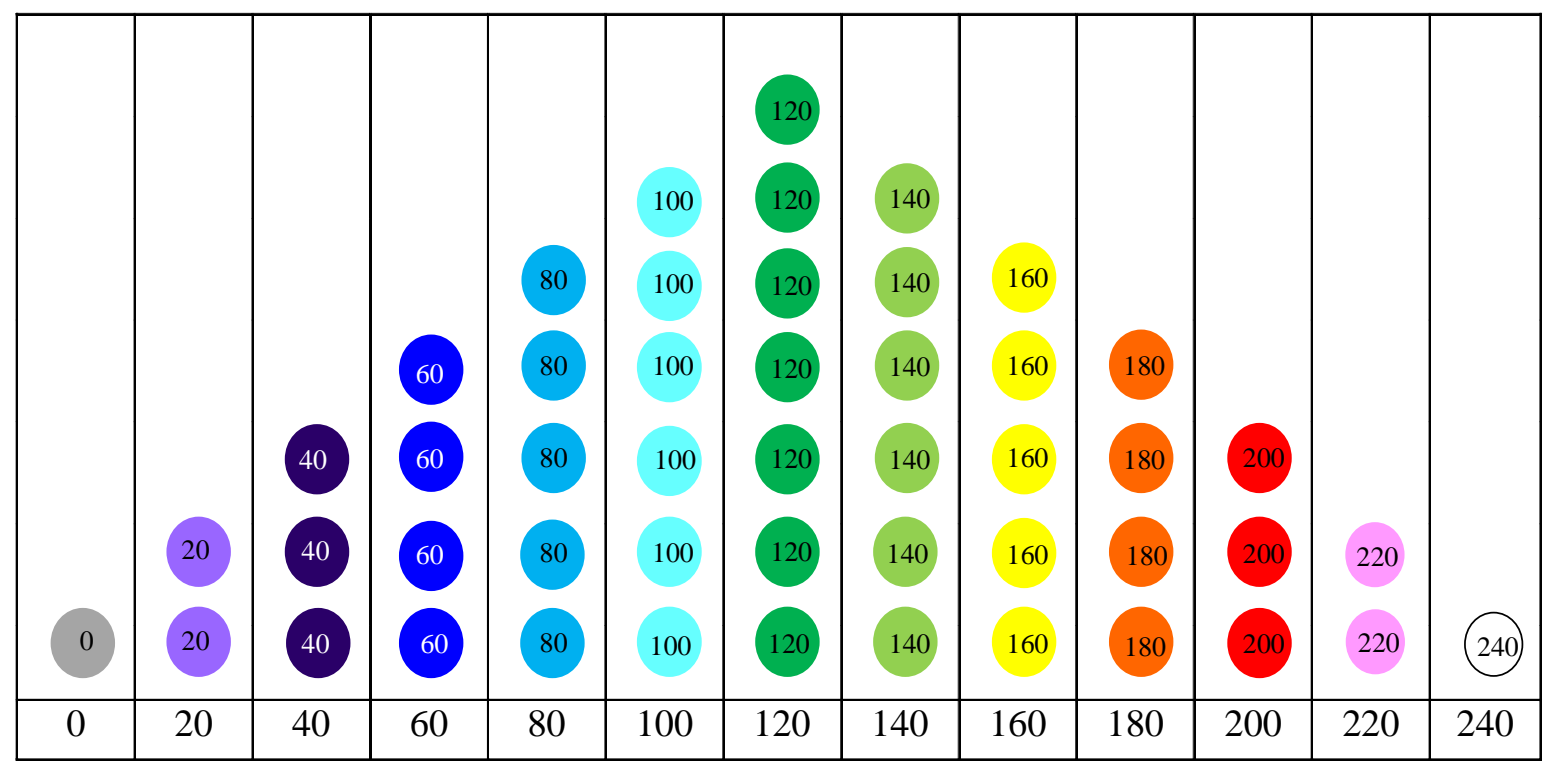

So the probability of being drawn differs for different values. For example, the probability that the minimum takes the value of $€ 60$ is $4 / 49(\approx 8 \%)$. The probability for the value $€ 120$ is $7 / 49(\approx 14 \%)$. Now, let us assume that a light blue ball with the value 100 was drawn. In this case, all players together must have invested at least $€ 100$ in order to prevent damage. If a single player has invested, say, a total of $€ 10$ into damage prevention during the ten rounds, she or he has $€ 30$ of credit in her or his personal account at the end of the game. If the group of players as a whole has invested $€ 100$ or more into damage prevention, the damage does not occur and this player receives $€ 30$ from the game. However, if the group as a whole has invested less than $€ 100$, the damage occurs and the player receives $€ 3$ (10\% of $€ 30$ ) from the game.

Please note the following feature of the game: Before the players decide how much they want to invest into preventing damage, they exchange non-binding suggestions for their common investment goal. Each player makes a suggestion of how much the group as a whole should invest into preventing damage over the total of ten rounds. After that, the suggestions made by all players and an average value from all suggestions are shown on the monitor. After round 
5, all players can make a new suggestion for the total investments to be made by the group over the ten rounds. After that, the suggestions made by each player and an average value for all suggestions are shown on the monitor.

\section{Example}

Here, you can see an example of the decisions made by the six players in one round (round 3).

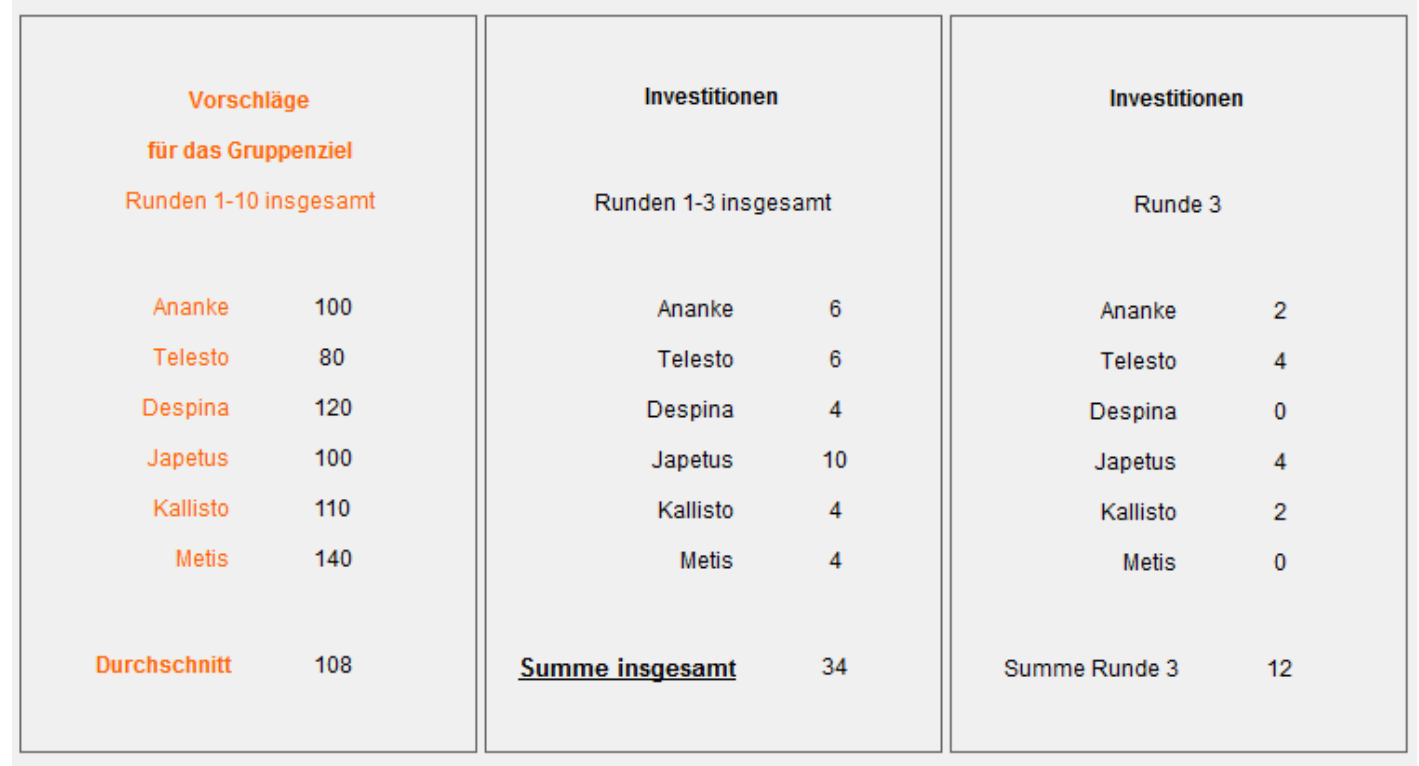

The right column shows the investments made in the current round (round 3). The players Ananke and Kallisto have invested $€ 2$ each, the players Telesto and Japetus have invested $€ 4$ each and Despina and Metis have not made any investments. In total, €12 were invested in this round. The middle column shows the cumulative investments made by each player from the first to the current round (rounds 1-3). The players Ananke and Telesto have each invested $€ 6$ in the first three rounds. Despina, Kallisto and Metis have each invested $€ 4$ and Japetus has invested $€ 10$ in the first three rounds. In total, $€ 34$ were invested in the first three rounds.

The left column shows the suggestions made by each player as to how much the group as a whole should invest into preventing damage over the ten rounds in total. For example, Metis 
suggests that the group should invest $€ 140$. The average of all suggestions is $€ 108$. In the game, you will see this information after each round.

"STOP sign" (oral explanation of the game)

\section{Control questions}

Please answer the following control questions.

a. How much does a player have to invest on average over the course of the ten rounds, if the group was to invest $€ 60$ in total? (please tick the correct answer)
$\mathrm{O} € 10$
$\mathrm{O} € 12$
$\mathrm{O} € 20$
$\mathrm{O} € 30$
$\mathrm{O} € 40$
$\mathrm{O} € 120$

b. How much does a player have to invest on average over the course of the ten rounds, if the group was to invest $€ 120$ in total? (please tick the correct answer)
$\mathrm{O} € 10$
$\mathrm{O} € 12$
$\mathrm{O} € 20$
$\mathrm{O} € 30$
$\mathrm{O} € 40$
$\mathrm{O} € 120$

c. How much does a player have to invest on average over the course of the ten rounds, if the group was to invest $€ 180$ in total? (please tick the correct answer)
$\mathrm{O} € 10$
$\mathrm{O} € 12$
$\mathrm{O} € 20$
$\mathrm{O} € 30$
$\mathrm{O} € 40$
$\mathrm{O} € 12$

d. How much does a player have to invest on average over the course of the ten rounds, if the group was to invest $€ 240$ in total? (please tick the correct answer)
$\mathrm{O} € 10$
$\mathrm{O} € 12$
$\mathrm{O} € 20$
$\mathrm{O} € 30$
$\mathrm{O} € 40$
$\mathrm{O} € 120$

e. Assume that the group has invested the minimum to prevent damage, and that you have invested $€ 16$ in total. How much cash do you get in the end of the game?

I get $€$ 
f. Take a look at the table in part 3 of the instructions. How much money do Despina and Japetus have in their personal accounts after round 3 ?

Despina has $€$ in her/his account.

Japetus has $€$ in her/his account.

g. Assume that you have invested a total of $€ 20$ over the ten rounds and the minimum investment value was not reached. How much cash do you get at the end of the game?
$\mathrm{O} € 0$
$\mathrm{O} € 2$
$\mathrm{O} € 4$
$\mathrm{O} € 6$
$\mathrm{O} € 8$
$\mathrm{O} € 20$

h. What is the probability of the minimum investment value to prevent damage being equal $€ 0$ ? (please tick the correct answer)
$\mathrm{O} 0 / 49(=0 \%)$
$\mathrm{O} 1 / 49(\approx 2 \%)$
$\mathrm{O} 4 / 49(\approx 8 \%)$
$\mathrm{O} 7 / 49(\approx 14 \%)$

i. What is the probability of the minimum investment value to prevent damage being equal $€ 240$ ? (please tick the correct answer)
O $0 / 49(=0 \%)$
$\mathrm{O} 1 / 49(\approx 2 \%)$
$\mathrm{O} 4 / 49(\approx 8 \%)$
$\mathrm{O} 7 / 49(\approx 14 \%)$

j. What is the probability of the minimum investment value to prevent damage being less or equal $€ 120$ ? (please tick the correct answer)
$\mathrm{O} 0 / 49(=0 \%)$
O $28 / 49(\approx 57 \%)$
$\mathrm{O} 43 / 49(\approx 88 \%)$
O $49 / 49(=100 \%)$

k. What is the probability of the minimum investment value to prevent damage being less or equal $€ 180$ ? (please tick the correct answer)
$\mathrm{O} 0 / 49(=0 \%)$
O $28 / 49(\approx 57 \%)$
$\mathrm{O} 43 / 49(\approx 88 \%)$
O $49 / 49(=100 \%)$

1. Assume that the group has invested a total of $€ 100$ over the ten rounds. The draw shows that the minimum total investment value to avoid damage is $€ 160$. Does the damage occur in this case? (please tick the correct answer)

O Yes $\quad \mathrm{O}$ No 
m. Assume that the group has invested a total of $€ 80$ over the ten rounds. The draw shows that the minimum total investment value to avoid damage is $€ 20$. Does the damage occur in this case? (please tick the correct answer)

O Yes $\quad$ O No

Please give us a hand signal after you have answered all control questions. We will come to you and check the answers. The game will begin after we have checked the answers of all players and answered any questions you may have. Good luck! 